Supporting Information

\title{
Calix[3]carbazole: One-Step Synthesis and Host-Guest Binding
}

Peng Yang*, Yong Jian ${ }^{\xi}$, Xue Zhou ${ }^{\xi}$, Gang Li, Tuo Deng, Hongyan Shen, Zhaozheng Yang and Zhangmin Tian

Key Laboratory of Structure-Based Drug Design and Discovery (Shenyang Pharmaceutical University), Ministry of Education, Shenyang 110016, P. R. China

*To whom correspondence should be addressed:

E-mail: yangpeng@syphu.edu.cn,pengyangcn05@hotmail.com

\section{Table of Contents}

1. NMR and HRMS Spectra of the Synthesized Compounds

2. VT-NMR Spectra and ${ }^{1}$ HNMR spectra of 2 at different concentrations

3. UV-Vis, Fluorescence Spectra and IR spectrum

4. 2D NMR Spectra of 2 in the Absence and Presence of Guests

5. Job Plot and HRMS Spectrum of 2-TEA Complexation 


\section{NMR and HRMS Spectra of the Synthesized Compounds}

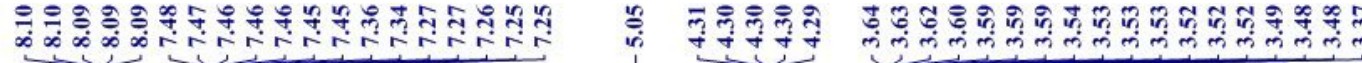

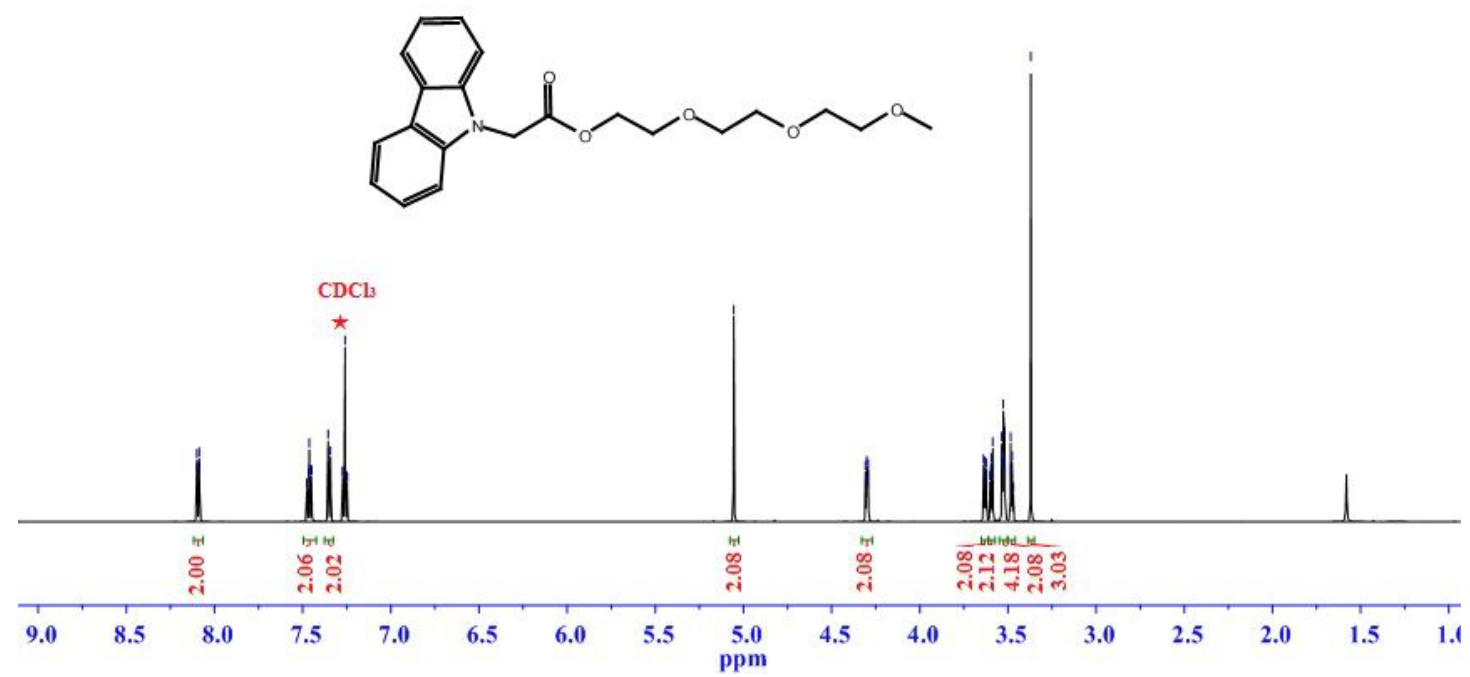

Figure S1. ${ }^{1} \mathrm{H}$ NMR of compound $1\left(600 \mathrm{MHz}, \mathrm{CDCl}_{3}\right)$ at $25{ }^{\circ} \mathrm{C}$
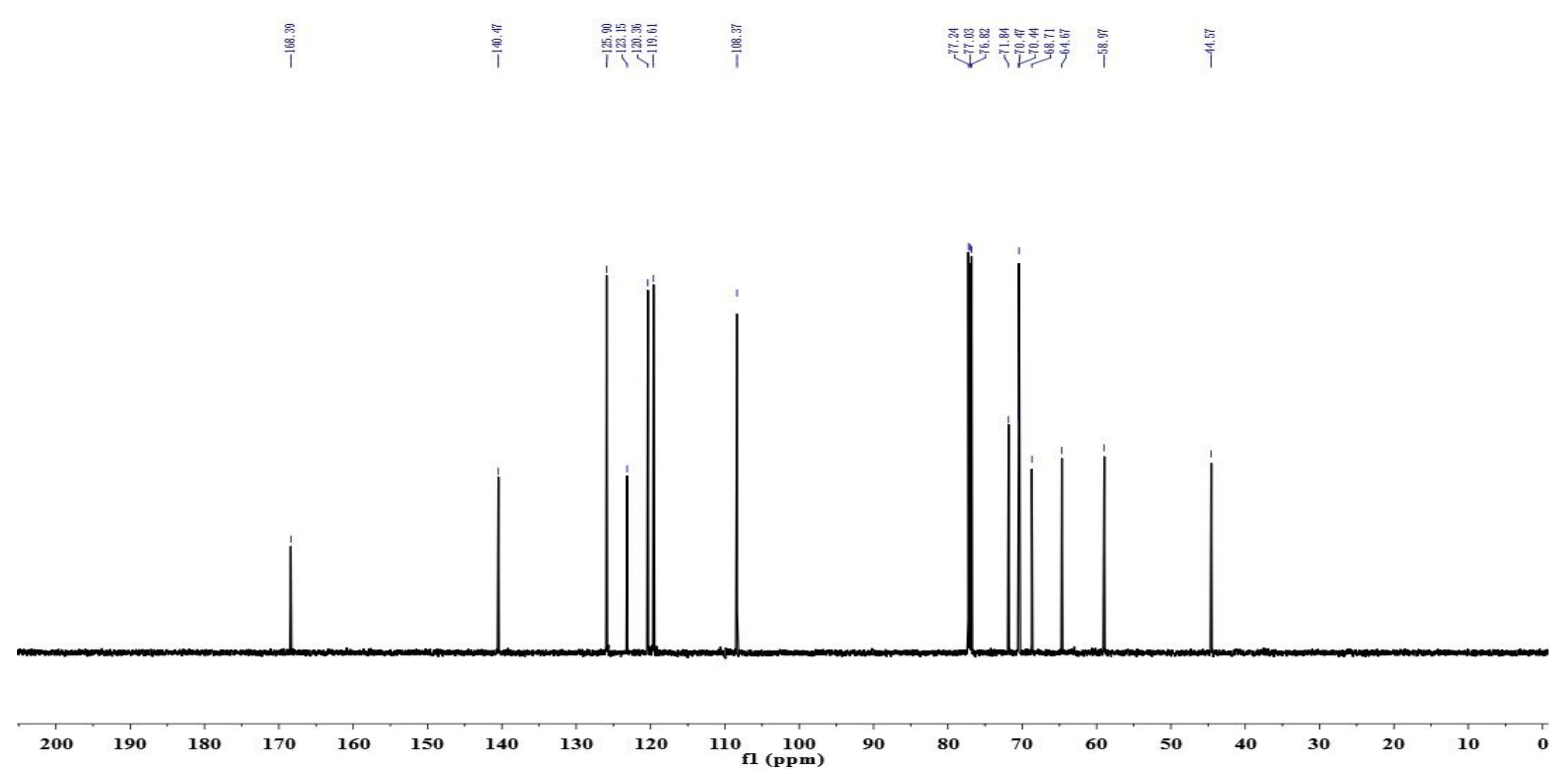

Figure S2. ${ }^{13} \mathrm{C}$ NMR of compound $1\left(150 \mathrm{MHz}, \mathrm{CDCl}_{3}\right)$ at $25{ }^{\circ} \mathrm{C}$ 


\section{Mass Spectrum Molecular Formula Report}

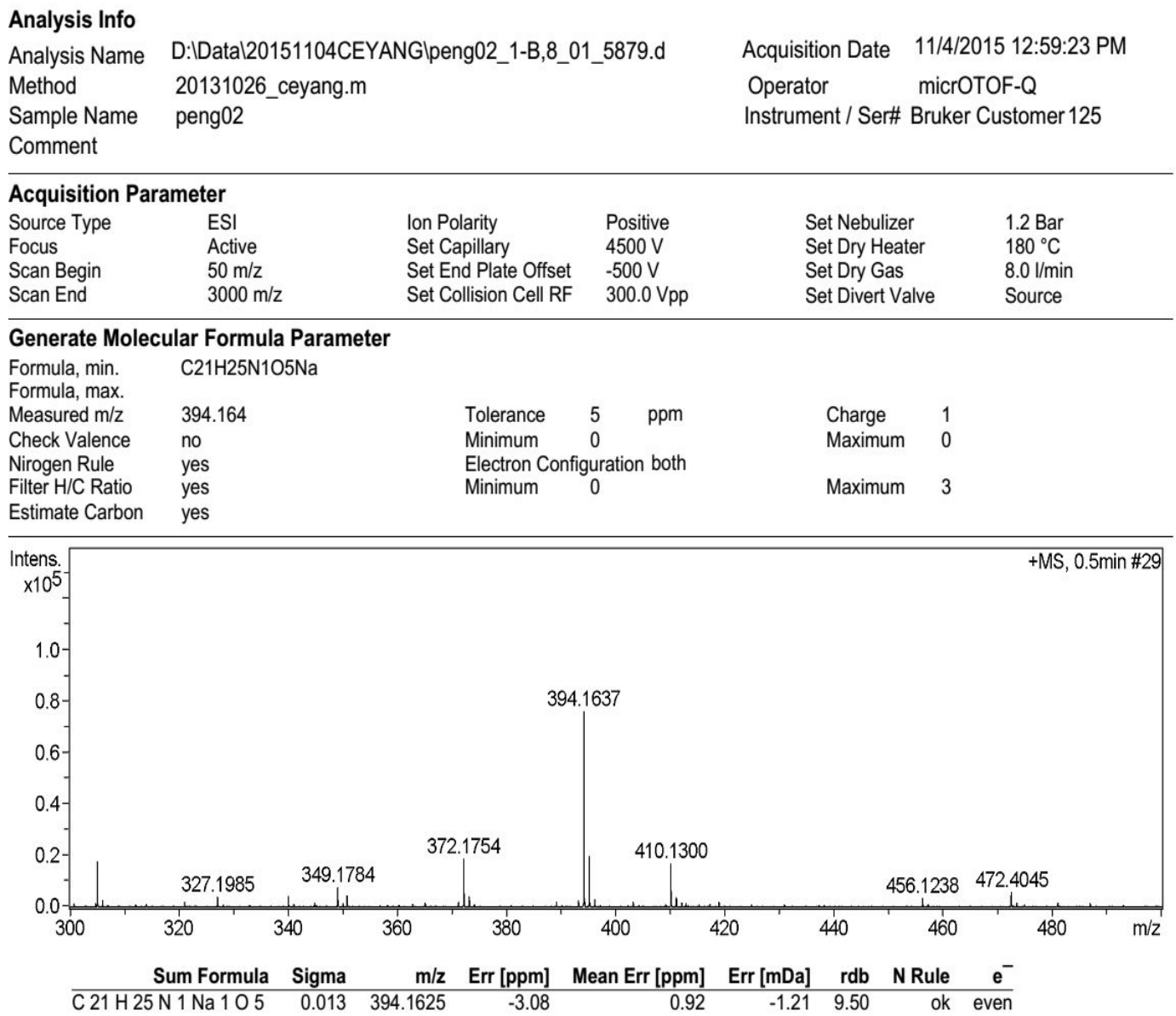

Figure S3. HRMS spectrum of compound 1 


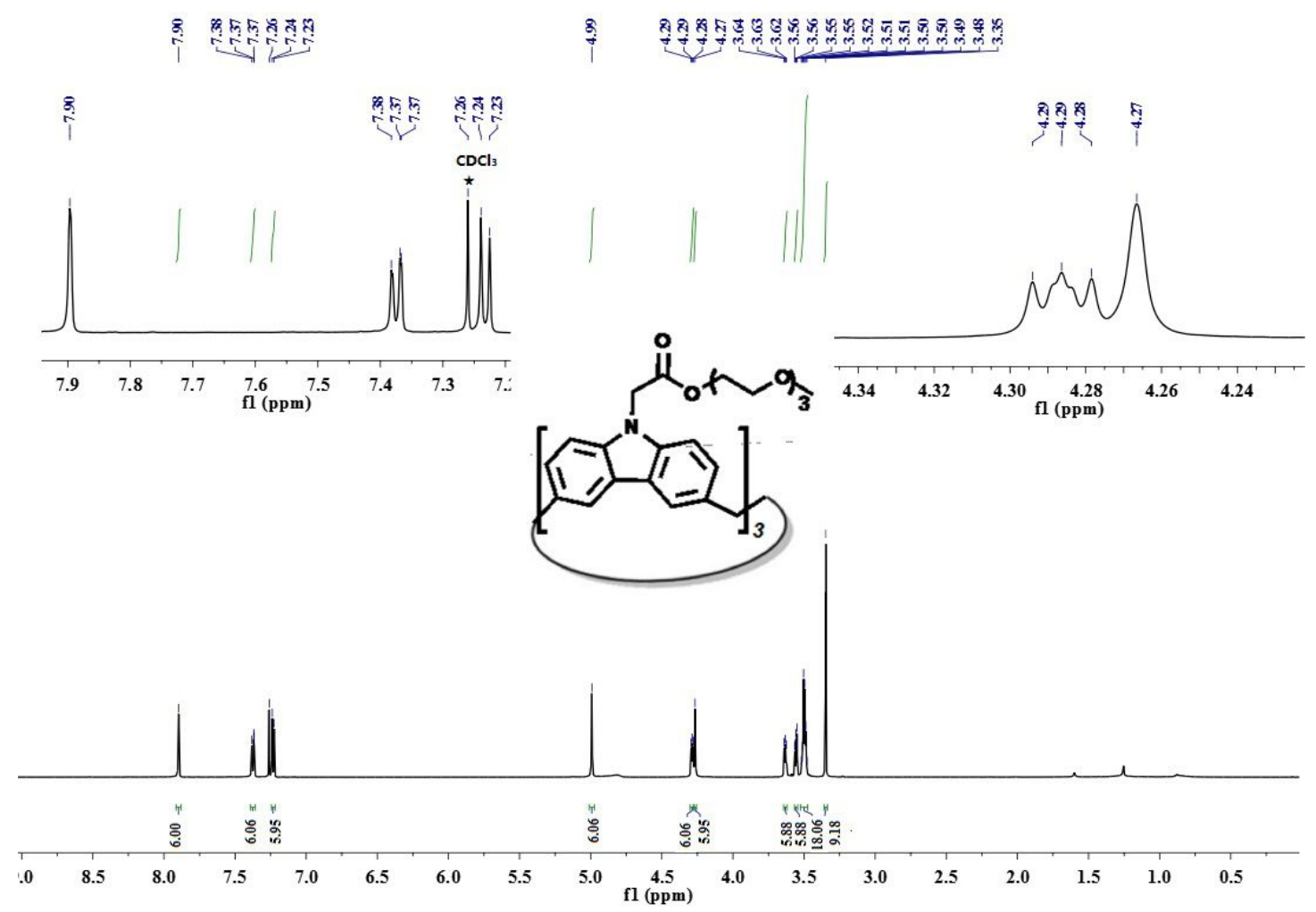

Figure S4. ${ }^{1} \mathrm{H}$ NMR of compound $2\left(600 \mathrm{MHz}, \mathrm{CDCl}_{3}\right)$ at $25{ }^{\circ} \mathrm{C}$

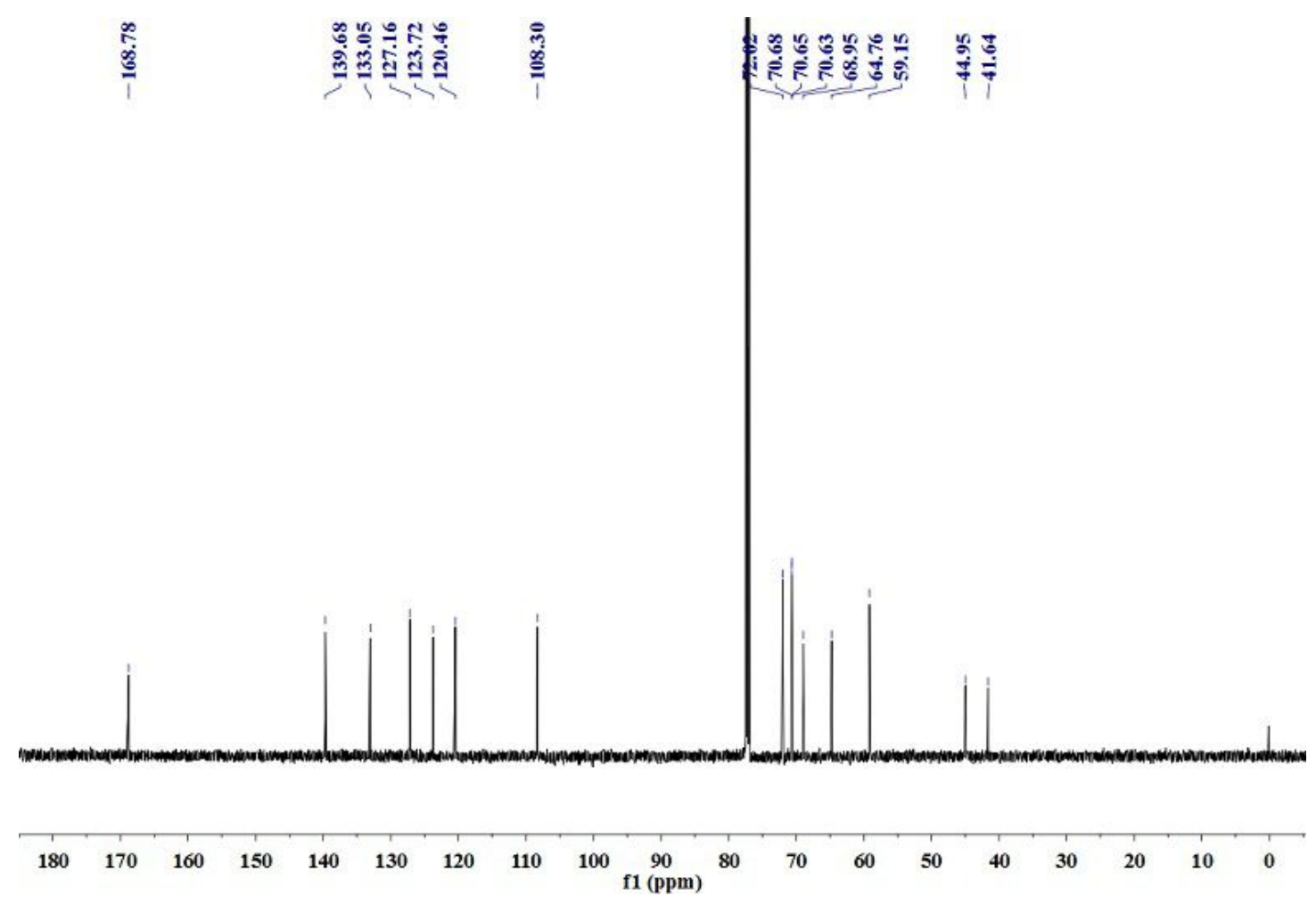

Figure S5. ${ }^{13} \mathrm{C}$-NMR of compound $2\left(600 \mathrm{MHz}, \mathrm{CDCl}_{3}\right)$ at $25{ }^{\circ} \mathrm{C}$ 


\section{Mass Spectrum Molecular Formula Report}

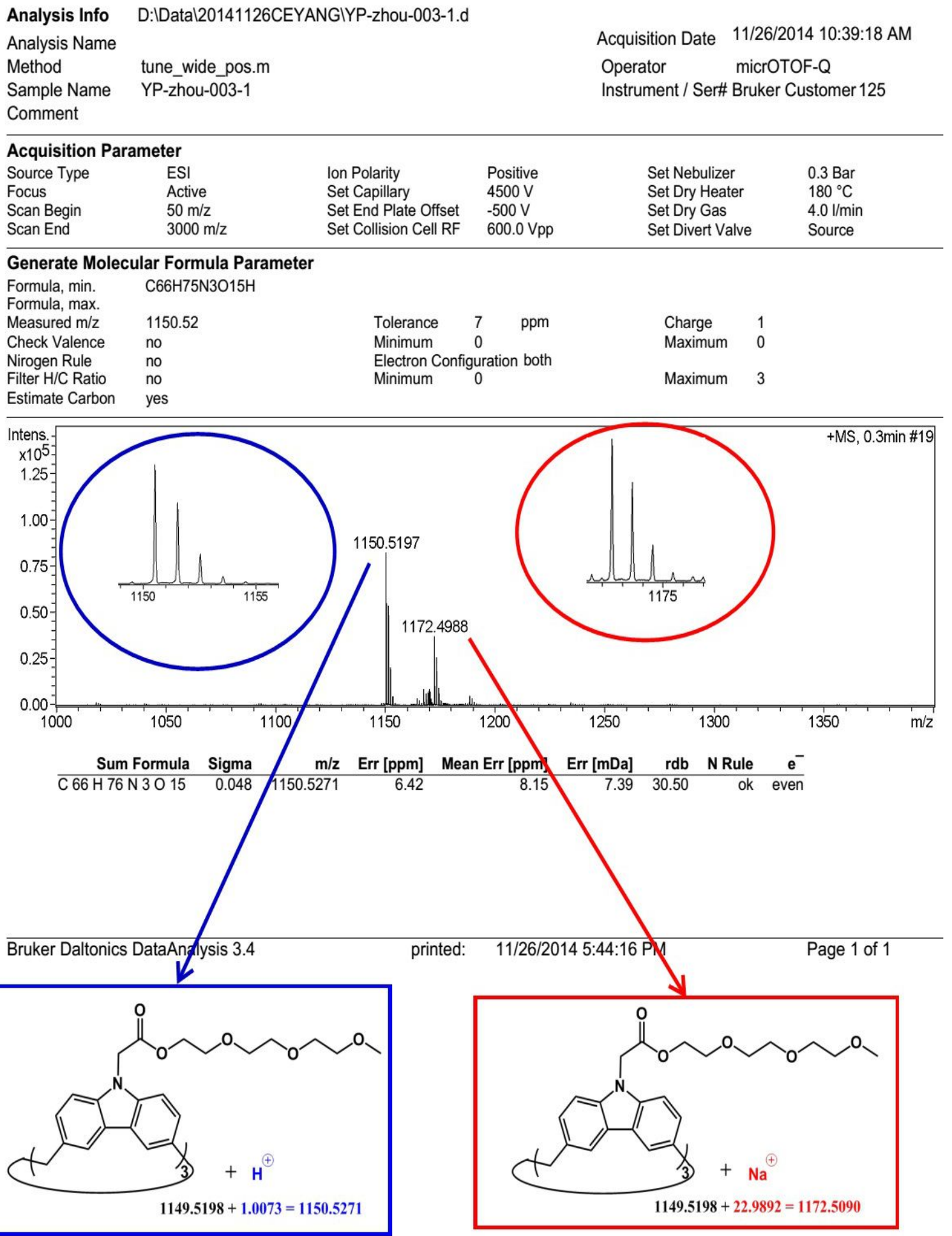

Figure S6. HRMS of compound 2 

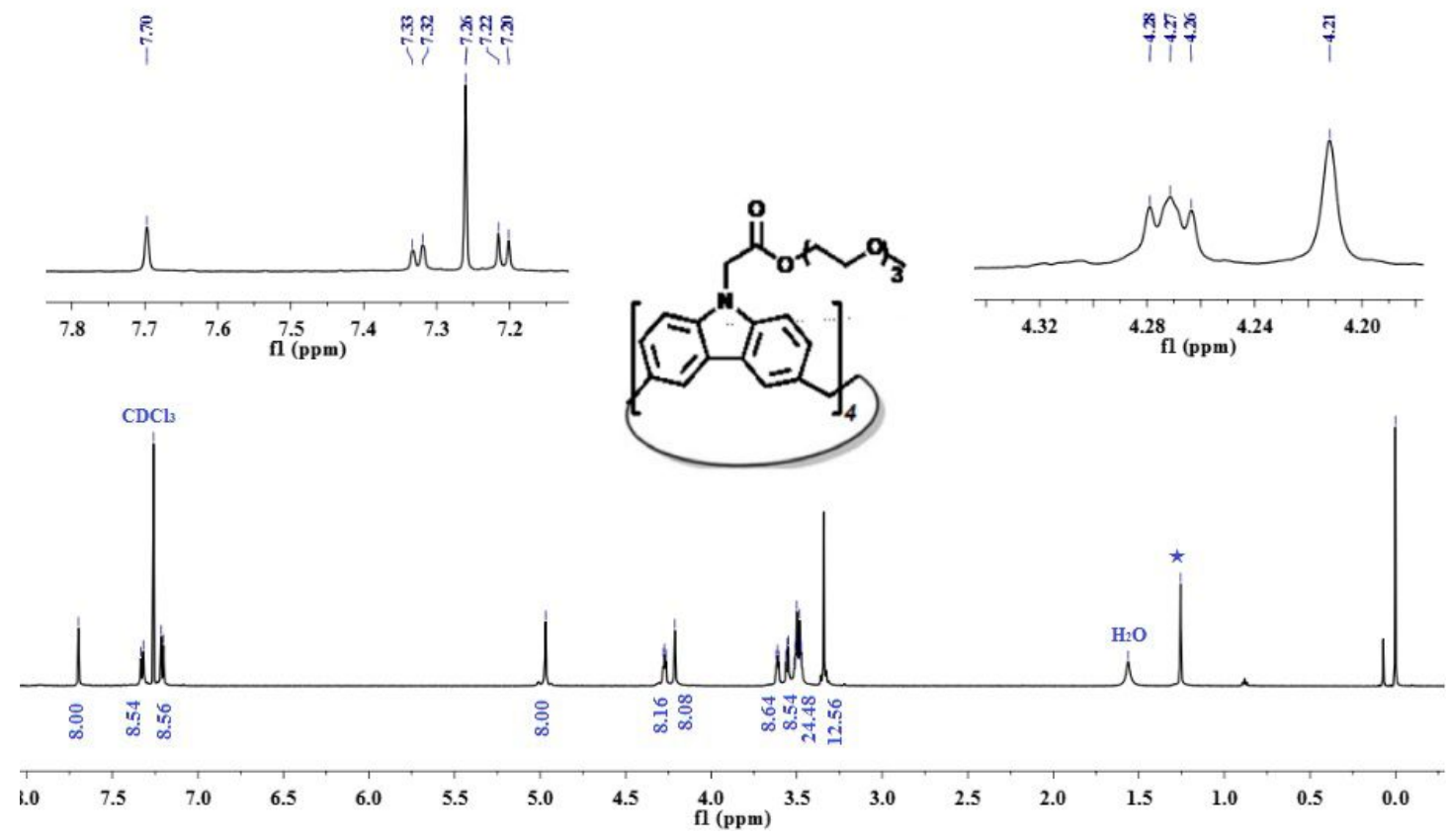

Figure S7. ${ }^{1} \mathrm{H}-\mathrm{NMR}$ of Calix[4]carbazole $\left(600 \mathrm{MHz}, \mathrm{CDCl}_{3}\right)$ at $25{ }^{\circ} \mathrm{C}\left({ }^{*}\right.$ : impurity $)$

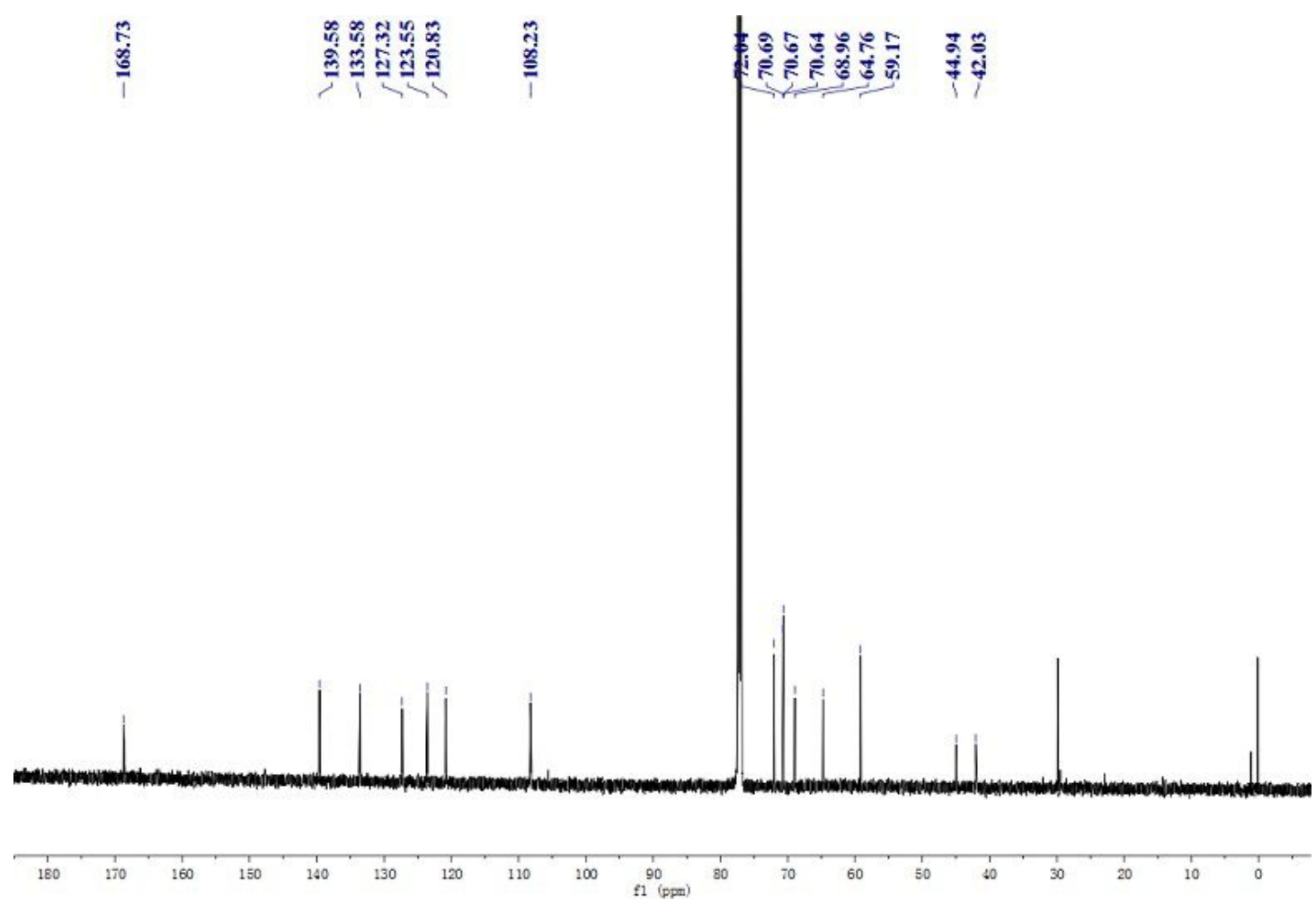

Figure S8. ${ }^{13} \mathrm{C}-\mathrm{NMR}$ of Calix[4]carbazole $\left(150 \mathrm{MHz}, \mathrm{CDCl}_{3}\right)$ at $25{ }^{\circ} \mathrm{C}$ 


\section{Mass Spectrum Molecular Formula Report}

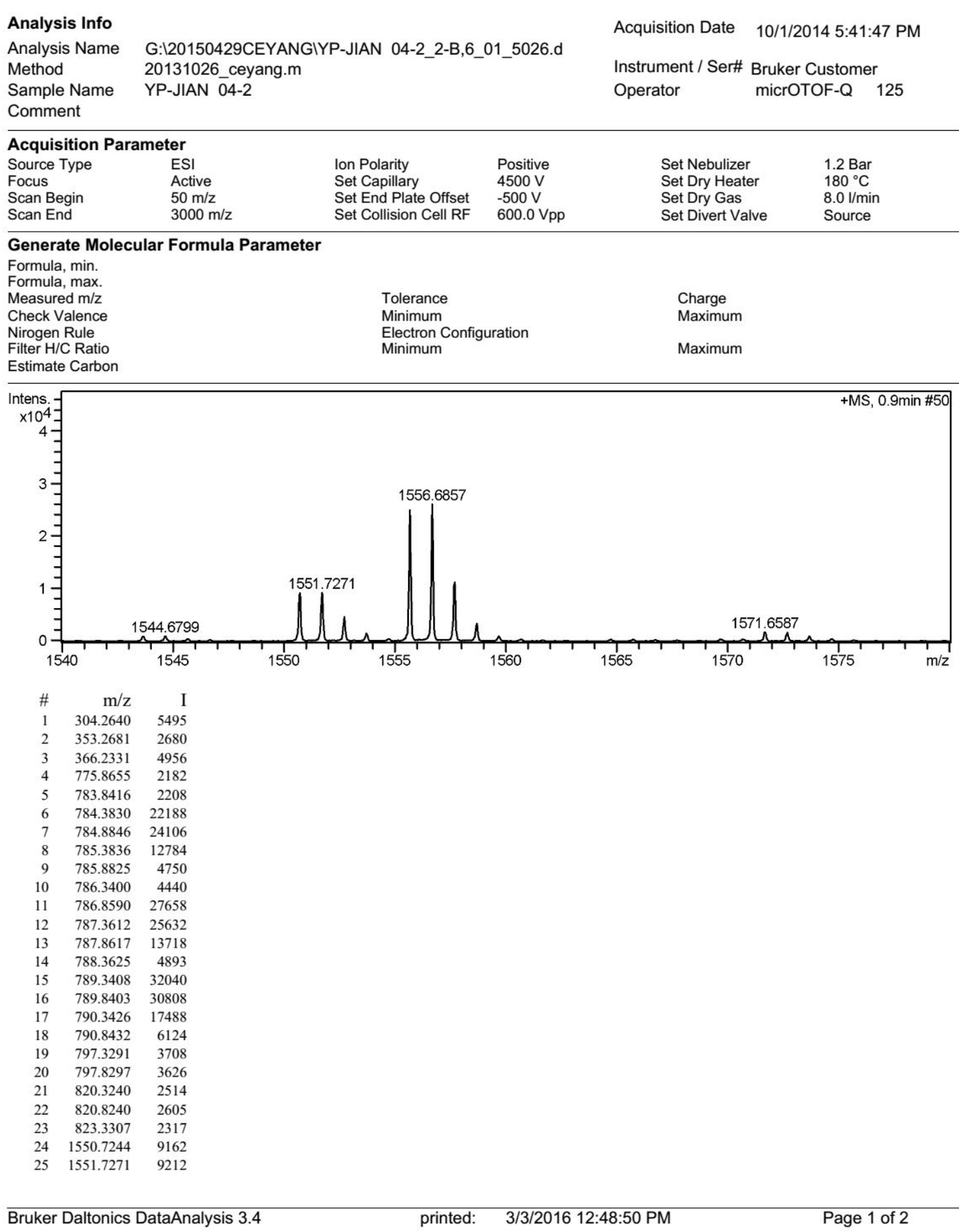


Mass Spectrum Molecular Formula Report

$\begin{array}{rrr}\# & \mathrm{~m} / \mathrm{z} & \mathrm{I} \\ 26 & 1552.7290 & 4577 \\ 27 & 1555.6820 & 24938 \\ 28 & 1556.6857 & 26058 \\ 29 & 1557.6861 & 11170 \\ 30 & 1558.6854 & 3316\end{array}$

Figure S9. HRMS of Calix[4]carbazole 


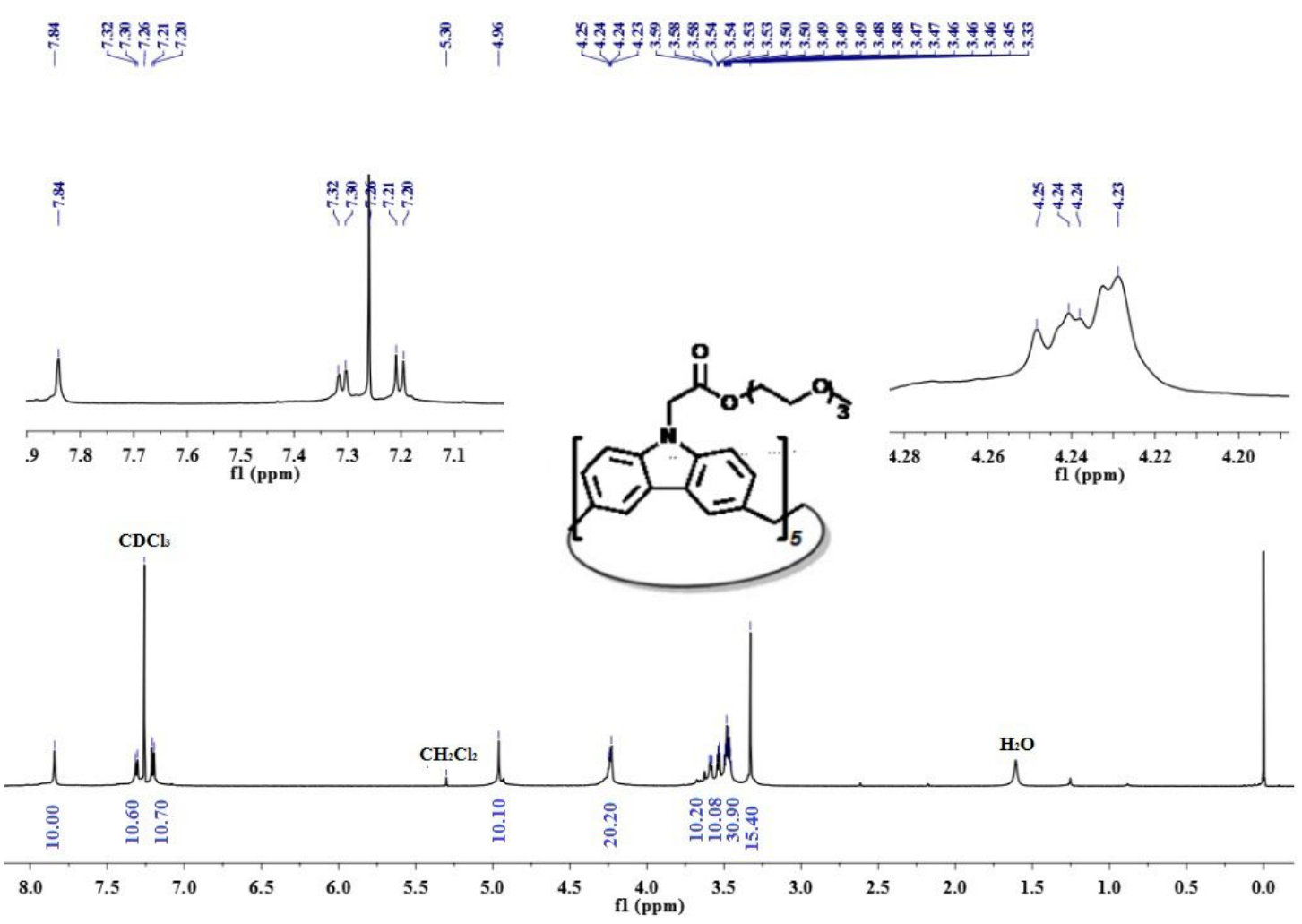

Figure S10. ${ }^{1} \mathrm{H}-\mathrm{NMR}$ of Calix[5]carbazole $\quad\left(600 \mathrm{MHz}, \mathrm{CDCl}_{3}\right)$ at $25{ }^{\circ} \mathrm{C}$

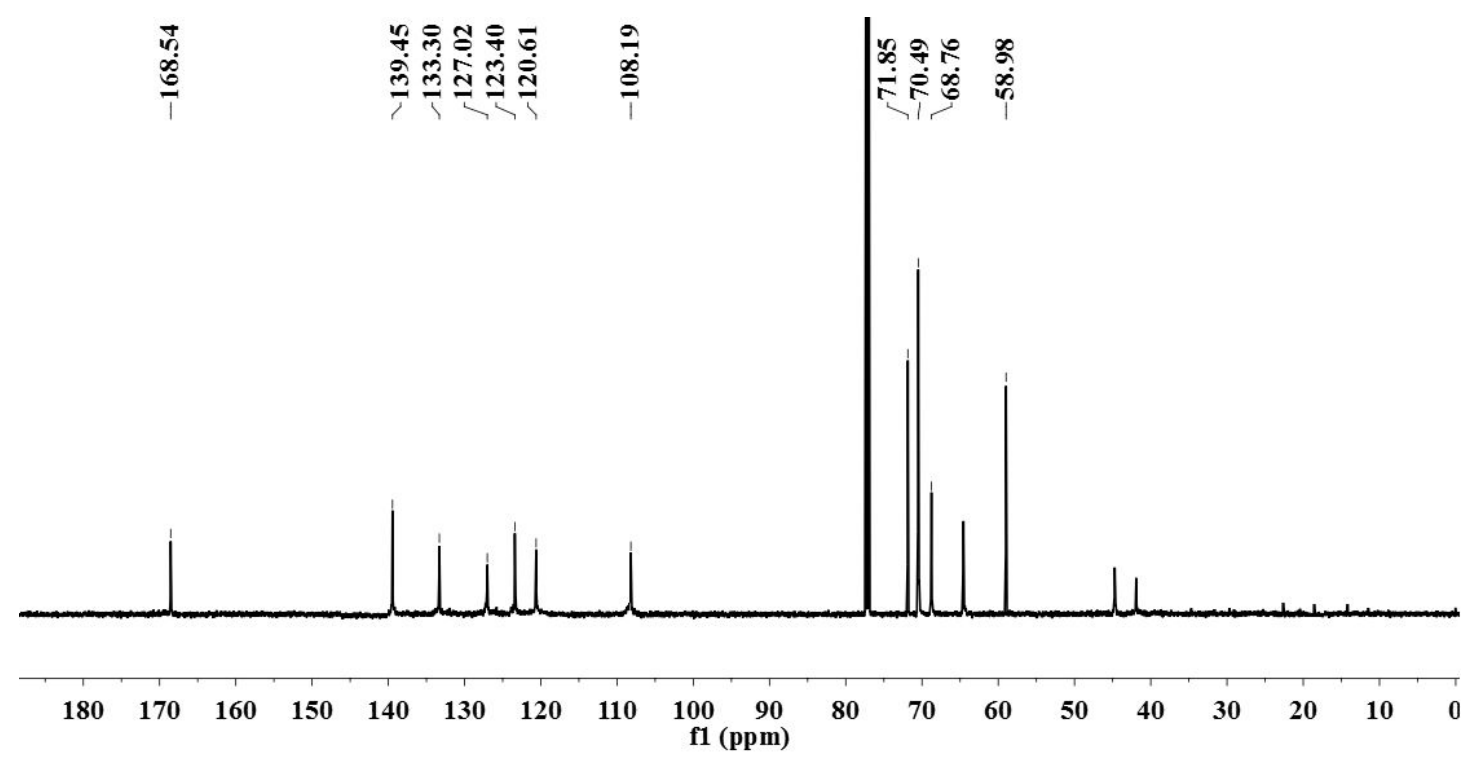

Figure S11. ${ }^{13} \mathrm{C}-\mathrm{NMR}$ of Calix[5]carbazole $\left(150 \mathrm{MHz}, \mathrm{CDCl}_{3}\right)$ at $25{ }^{\circ} \mathrm{C}$ 


\section{Mass Spectrum Molecular Formula Report}

Analysis Info

Analysis Name

Method

D:IDatal20141114CEYANGIYP-Zhou-004_1-a,6_01_4213.d 20131026_ceyang.m

YP-Zhou-004
Acquisition Date

Instrument / Ser\# Bruker Custome

Operator

micrOTOF-Q 125

Comment

\begin{tabular}{llllll}
\hline \multicolumn{2}{l}{ Acquisition Parameter } & & & & \\
Source Type & ESI & Ion Polarity & Positive & Set Nebulizer & 1.2 Bar \\
Focus & Active & Set Capillary & $4500 \mathrm{~V}$ & Set Dry Heater & $180^{\circ} \mathrm{C}$ \\
Scan Begin & $50 \mathrm{~m} / \mathrm{z}$ & Set End Plate Offset & $-500 \mathrm{~V}$ & Set Dry Gas & $8.0 \mathrm{~V} / \mathrm{min}$ \\
Scan End & $3000 \mathrm{~m} / \mathrm{z}$ & Set Collision Cell RF & $600.0 \mathrm{Vpp}$ & Set Divert Valve & Source
\end{tabular}

Scan End $3000 \mathrm{~m} / \mathrm{z}$

Formula, $\min$.

Formula, max

Measured $\mathrm{m} / \mathrm{z}$

Check Valence

Nirogen Rule

Filter H/C Ratio

Estimate Carbon

Set Collision Cell RF $\quad 600.0$ Vpp

Set Divert Valve

Source

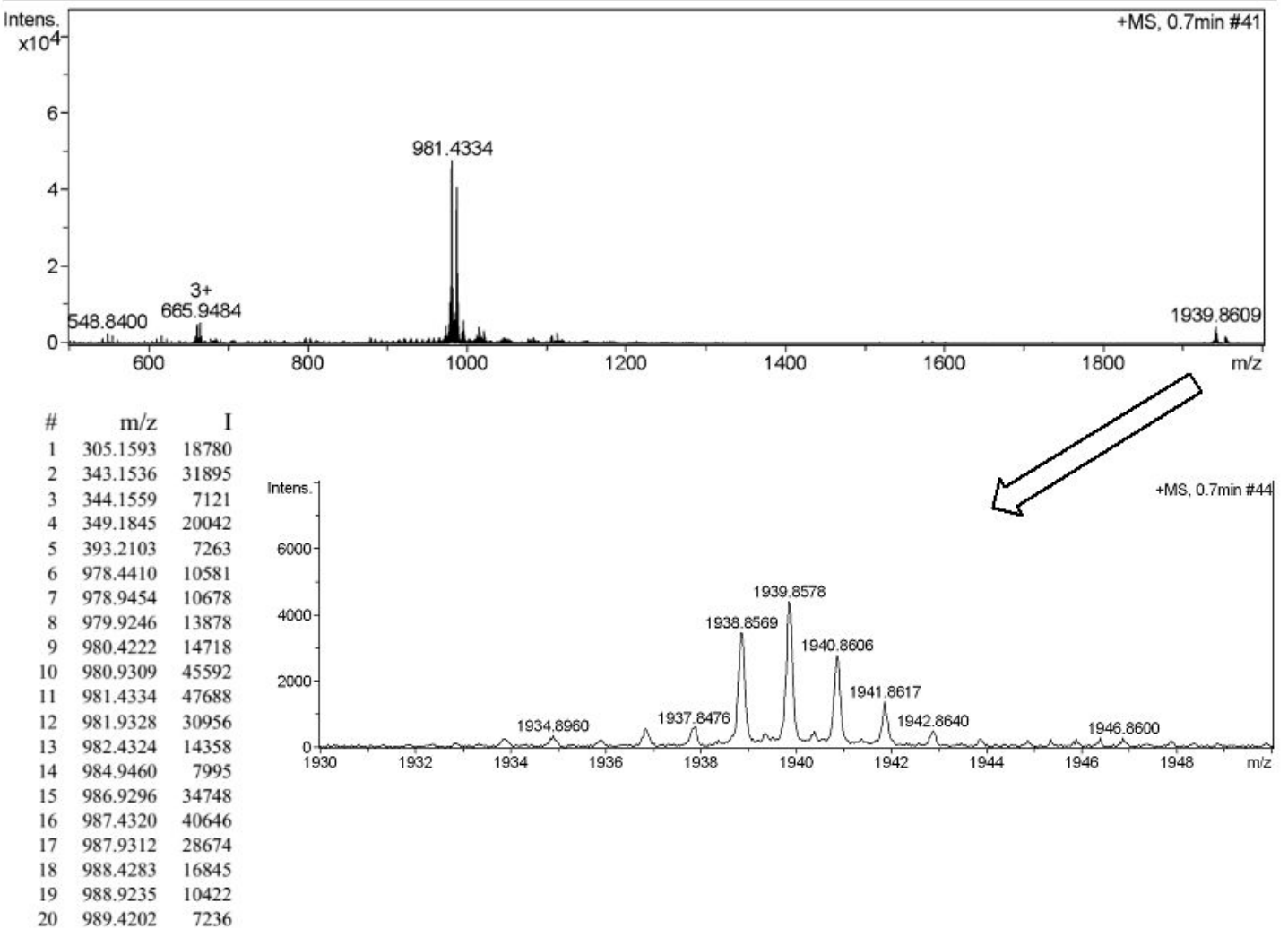

Figure S12. HRMS of Calix[5]carbazole 


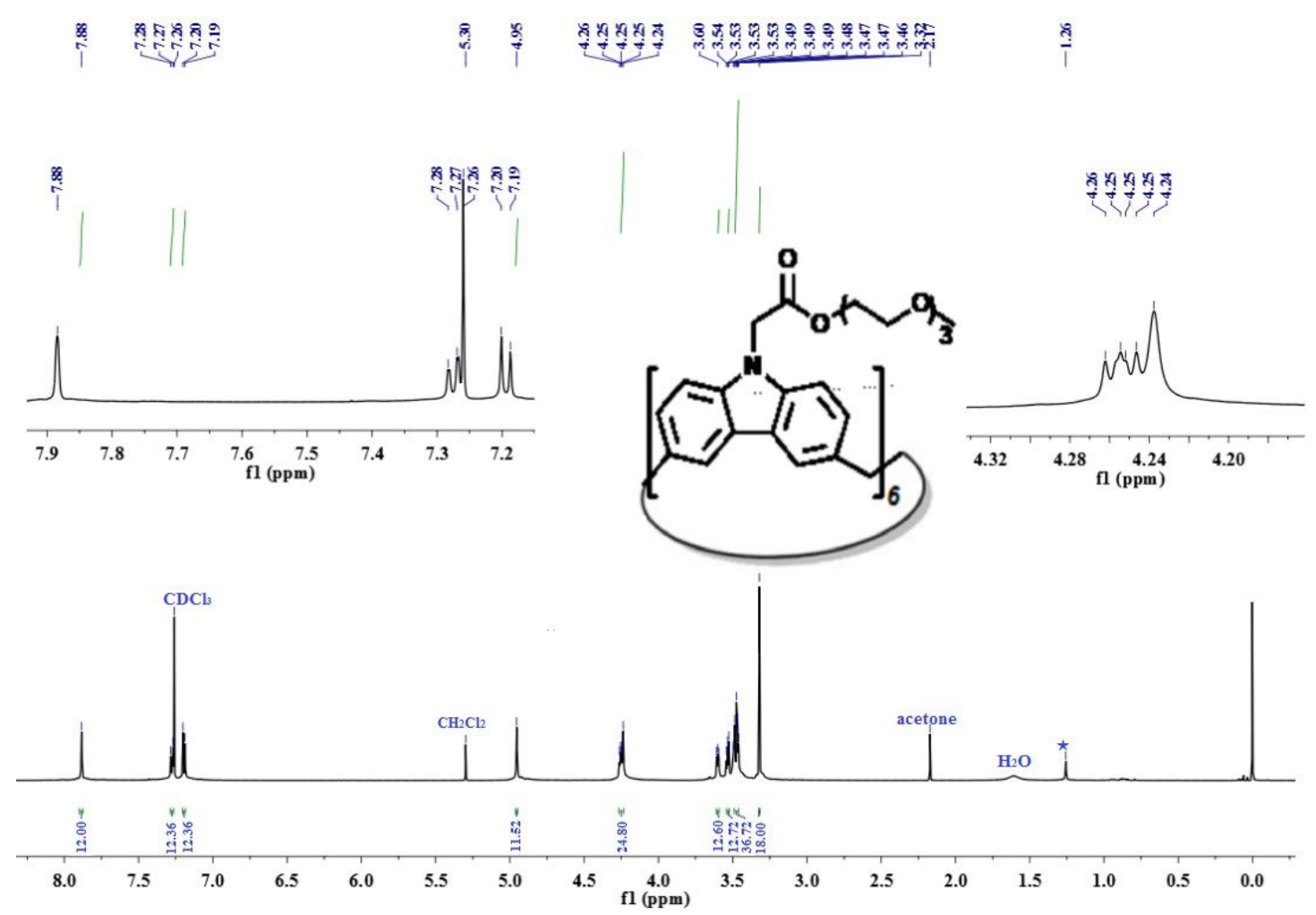

Figure S13. ${ }^{1} \mathrm{H}-\mathrm{NMR}$ of Calix[6]carbazole $\left(600 \mathrm{MHz}, \mathrm{CDCl}_{3}\right)$ at $25{ }^{\circ} \mathrm{C} \quad\left({ }^{*}\right.$ : impurity)

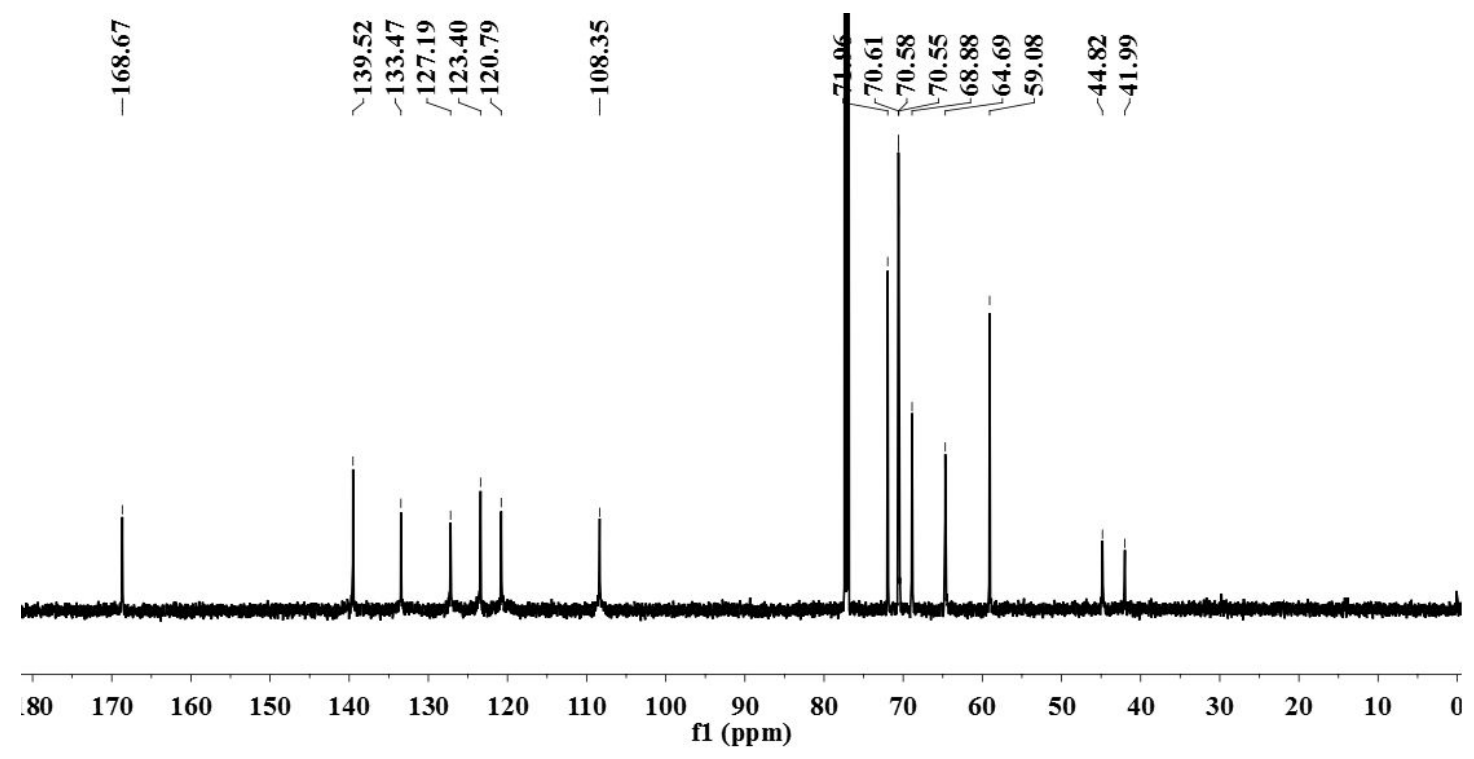

Figure S14. ${ }^{13} \mathrm{C}-\mathrm{NMR}$ of Calix[6]carbazole $\left(150 \mathrm{MHz}, \mathrm{CDCl}_{3}\right)$ at $25{ }^{\circ} \mathrm{C}$ 


\section{Mass Spectrum Molecular Formula Report}

Analysis Info

Analysis Name

Method

D:IDatal20150429CEYANGIYP-JIAN06.d

20131026_ceyang.m

YP-JIAN06

Sample Name

Comment
Acquisition Date

10/1/2014 7:27:37 PM

Instrument / Ser\# Bruker Customer

Operator

micrOTOF-Q 125

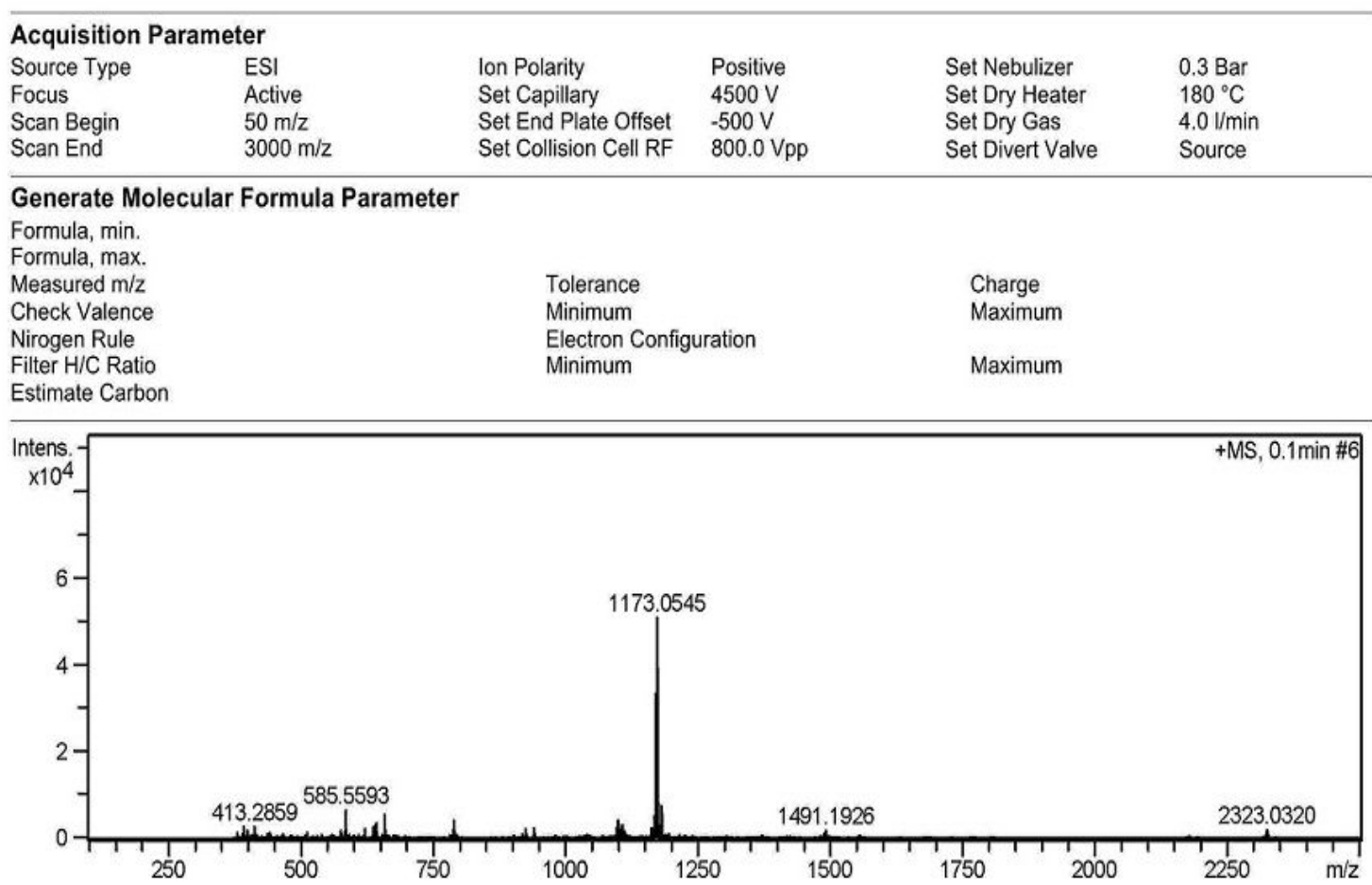

$\begin{array}{rrr}\# & \mathrm{~m} / \mathrm{z} & \mathrm{I} \\ 1 & 585.5593 & 6449 \\ 2 & 659.3153 & 5442 \\ 3 & 789.7054 & 4224 \\ 4 & 1100.0036 & 4200 \\ 5 & 1168.0915 & 5166 \\ 6 & 1168.5939 & 4000 \\ 7 & 1169.5466 & 5776 \\ 8 & 1170.0639 & 25741 \\ 9 & 1170.5697 & 33432 \\ 10 & 1171.0712 & 24172 \\ 11 & 1171.5722 & 11198 \\ 12 & 1172.0719 & 5222 \\ 13 & 1172.5528 & 36728 \\ 14 & 1173.0545 & 50933 \\ 15 & 1173.5546 & 39124 \\ 16 & 1174.0547 & 20775 \\ 17 & 1174.5536 & 8223 \\ 18 & 1180.5377 & 5233 \\ 19 & 1181.0396 & 7445 \\ 20 & 1181.5396 & 5810\end{array}$

Figure S15. HRMS of Calix[6]carbazole 
2. VT ${ }^{1} \mathrm{HNMR}$ of 2 and Its Concentration-Dependent ${ }^{1} \mathrm{HNMR}$

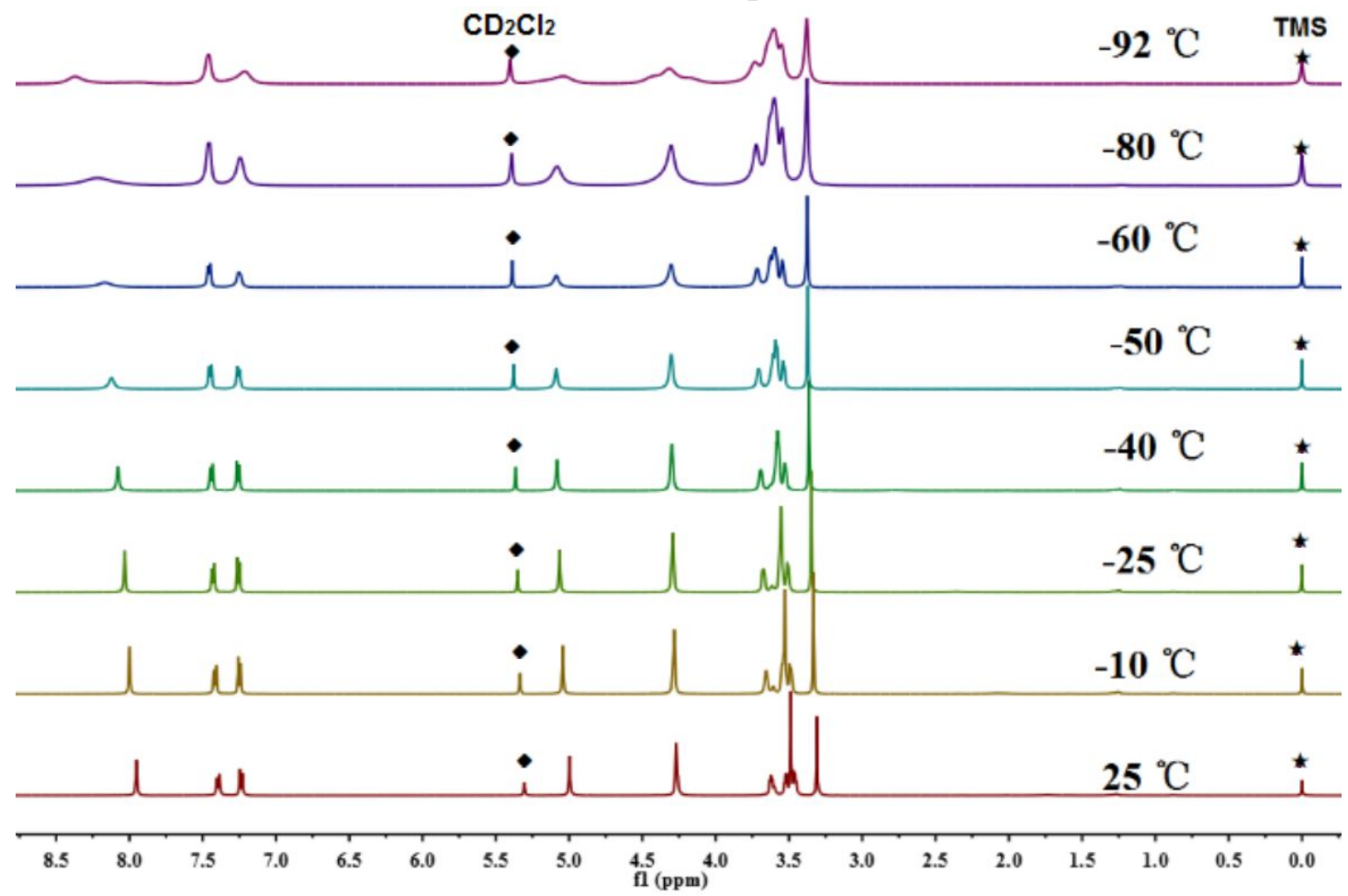

(a)

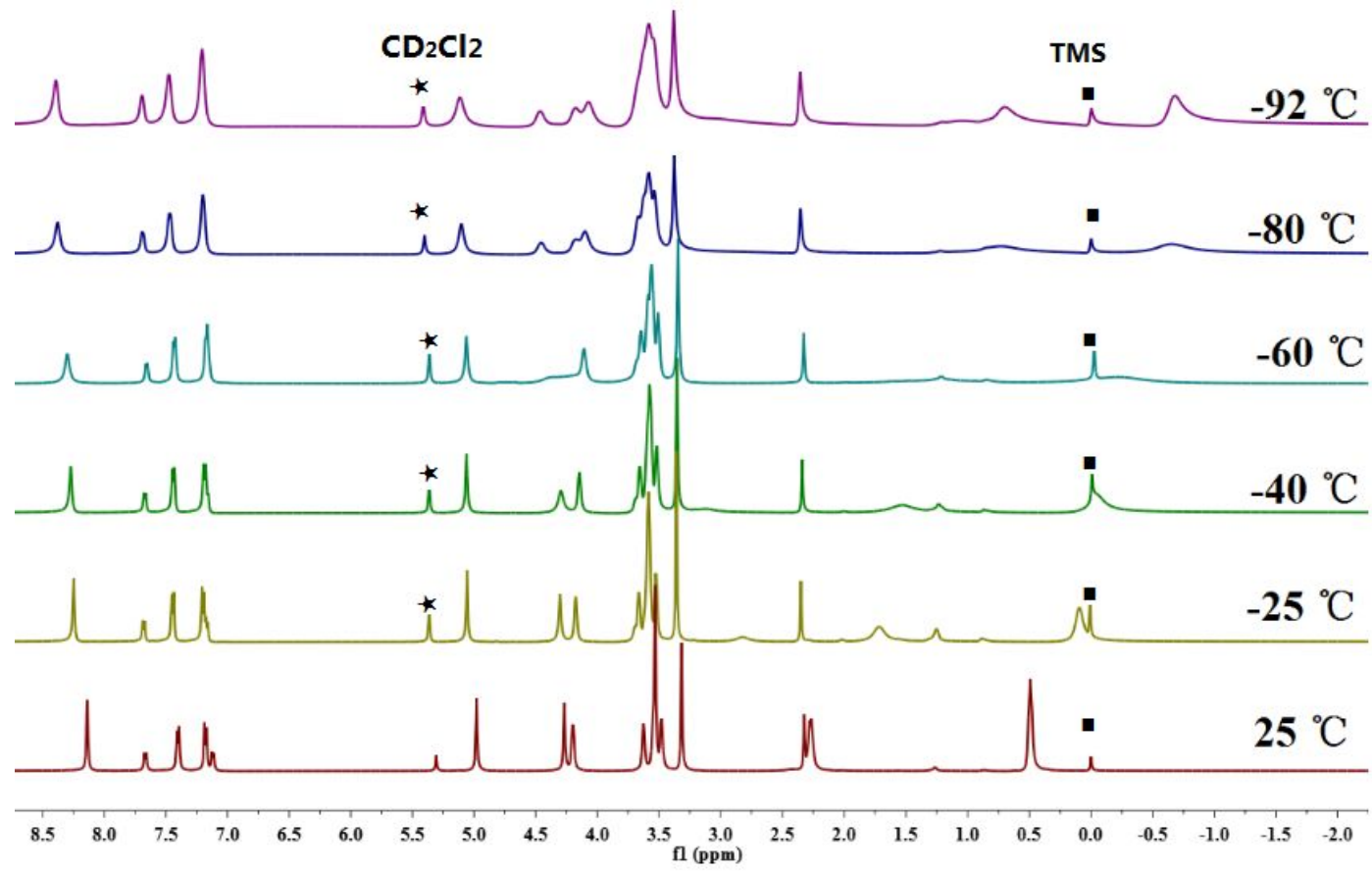

(b)

Figure S16. (a): VT-NMR of $2\left(500 \mathrm{MHz}, \mathrm{CD}_{2} \mathrm{Cl}_{2}\right)\left(25^{\circ} \mathrm{C},-10^{\circ} \mathrm{C},-25^{\circ} \mathrm{C},-40^{\circ} \mathrm{C},-50^{\circ} \mathrm{C},-\mathbf{- 6 0}^{\circ} \mathrm{C},-80^{\circ} \mathrm{C},-92^{\circ} \mathrm{C}\right)$; (b)VT-NMR of an equimolar mixture of [2+TEA] $\left(500 \mathrm{MHz}, \mathrm{CD}_{2} \mathrm{Cl}_{2}\right)\left(25^{\circ} \mathrm{C},-25^{\circ} \mathrm{C},-40^{\circ} \mathrm{C},-60^{\circ} \mathrm{C},-80^{\circ} \mathrm{C},-92^{\circ} \mathrm{C}\right)$; 


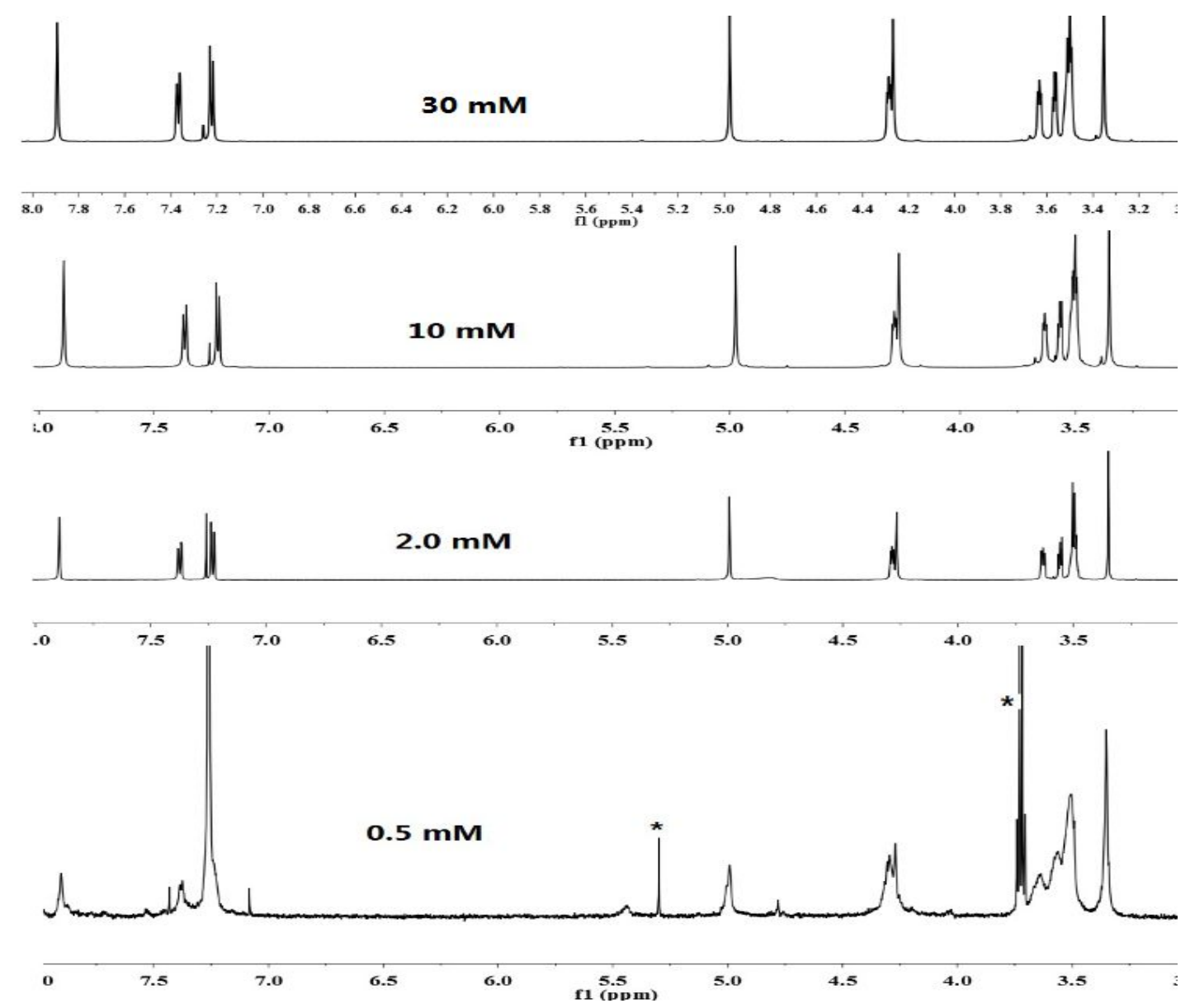

Figure S17. ${ }^{1} \mathrm{HNMR}$ of 2 at $0.5,2.0,10$ and $30 \mathrm{mM}$, respectively in $\mathrm{CDCl}_{3}$ at $25{ }^{\circ} \mathrm{C}(*$ : contamination)

Note: The peaks of 2 at $30 \mathrm{mM}$ are not shifted or broaden compared to those at $10 \mathrm{mM}, 2.0 \mathrm{mM}$ or $0.5 \mathrm{mM}$, which indicate that it is not aggregated even at $30 \mathrm{mM}$. The signals of 2 at $0.5 \mathrm{mM}$ is poor, though, it is recorded and listed here to preclude the possibility of aggregation of $\mathbf{2}$ at such a concentration.

\section{UV-Vis, Fluorescence Spectra and IR spectrum}

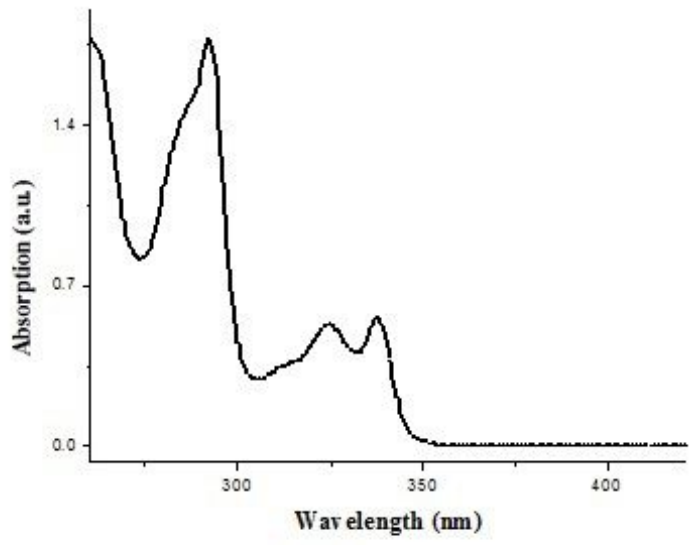

(a)

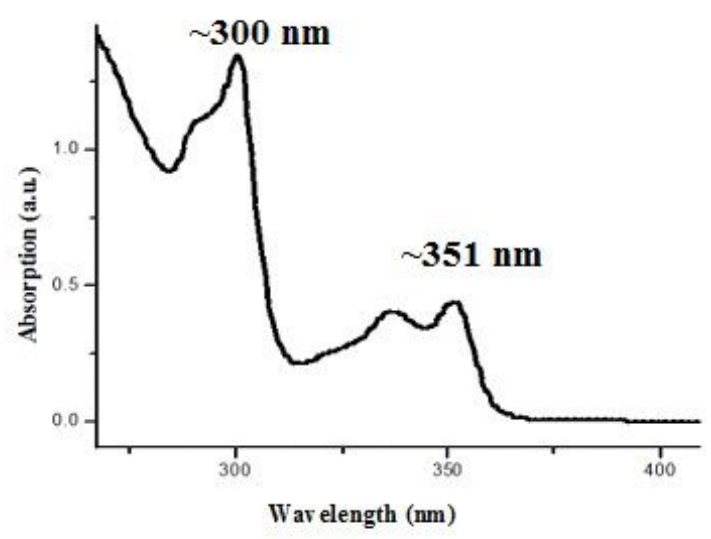

(b)

Figure S18. UV-vis spectra of (a), $1(150 \mu \mathrm{M})$ and $(\mathbf{b}), 2(50 \mu \mathrm{M})$ in $\mathrm{CHCl}_{3}$ at $25{ }^{\circ} \mathrm{C}$ (1: $\left.\lambda_{\max }=\sim 340 \mathrm{~nm}\left(\varepsilon: 3.6 \times 10^{3} \mathrm{~L} \mathrm{M}^{-1} \mathrm{~cm}^{-1}\right) ; 2: \lambda_{\max }=\sim 351 \mathrm{~nm}\left(\varepsilon: 1.3 \times 10^{4} \mathrm{~L} \mathrm{M}^{-1} \mathrm{~cm}^{-1}\right)\right)$ 


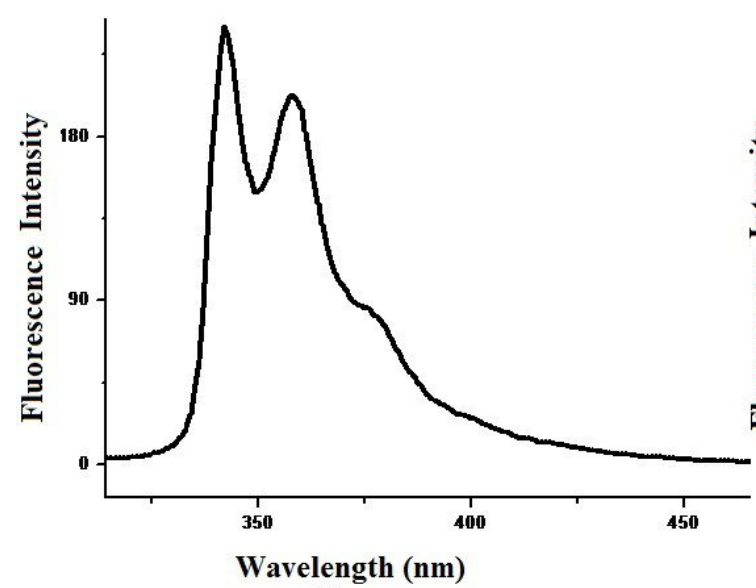

(a)

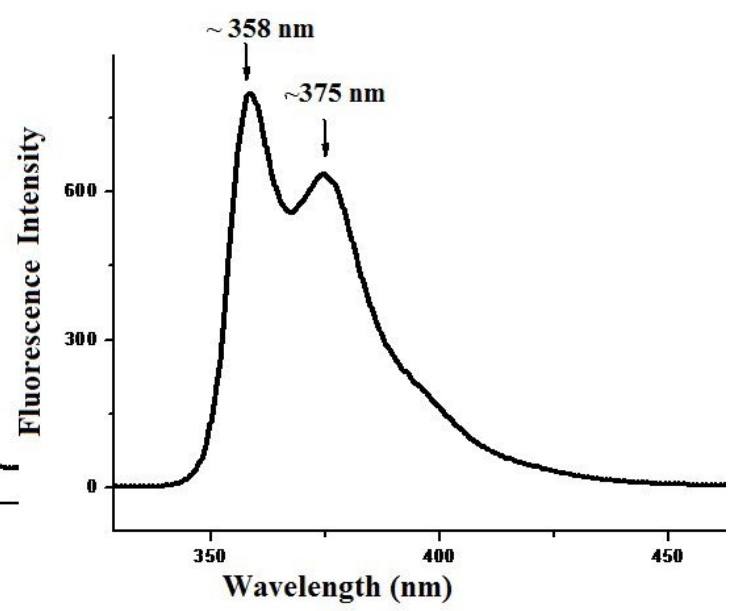

(b)

Figure S19. Fluorescent spectra of (a): 1 and (b): 2 in $\mathrm{CH}_{2} \mathrm{Cl}_{2}$

Note: The quantum yields of compound 1 and 2 in $\mathrm{CH}_{2} \mathrm{Cl}_{2}$ are $\Phi_{1}=0.16, \Phi_{2}=0.41$ receptively, determined by a relative comparison procedure using quinine as standard $(\Phi=0.54$ in $0.05 \mathrm{M}$ sulfuric acid ). The general equation used in the determination of relative quantum yields is as follows: $\Phi_{u}=\left(\Phi_{s} \times F_{u} \times A_{s} \times \lambda_{\text {exs }} \times \eta_{u}^{2}\right) /\left(F_{s} \times A_{u}\right.$ $\times \lambda_{\text {exu }} \times \eta_{\mathrm{s}}^{2}$ ). where $\Phi$ is the quantum yields, $F$ is the integrated area under the corrected emission spectrum, $A$ is the absorption at the excitation wavelength, $\lambda_{e x}$ is the excitation wavelength, $\eta$ is the refractive index of the solution and the subscripts ' $u$ ' and 's' refer to the unknown and the standard, respectively.

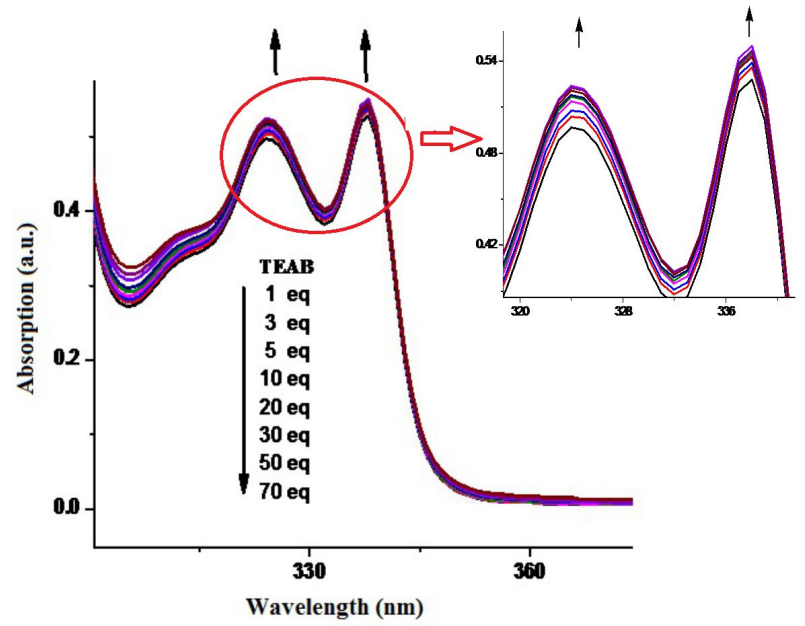

(a)

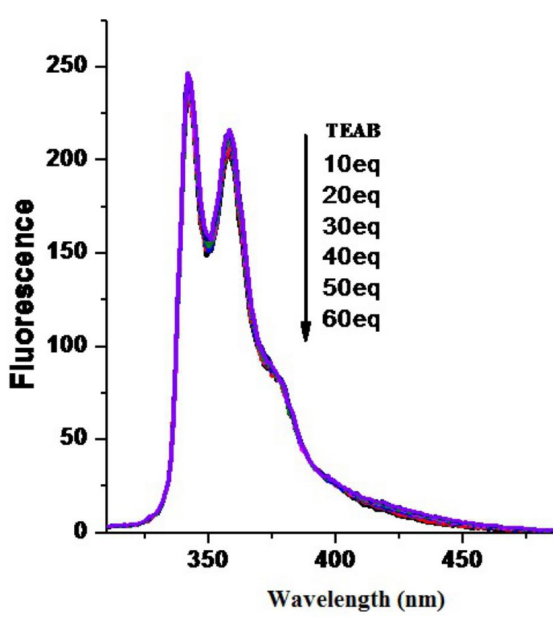

(b)

Figure S20. (a)UV-vis in $\mathrm{CHCl}_{3}$; (b) fluorescent spectra in $\mathrm{CH}_{2} \mathrm{Cl}_{2}$; of the control compound $\mathbf{1}$ upon addition of TEAB at $25{ }^{\circ} \mathrm{C}$ 

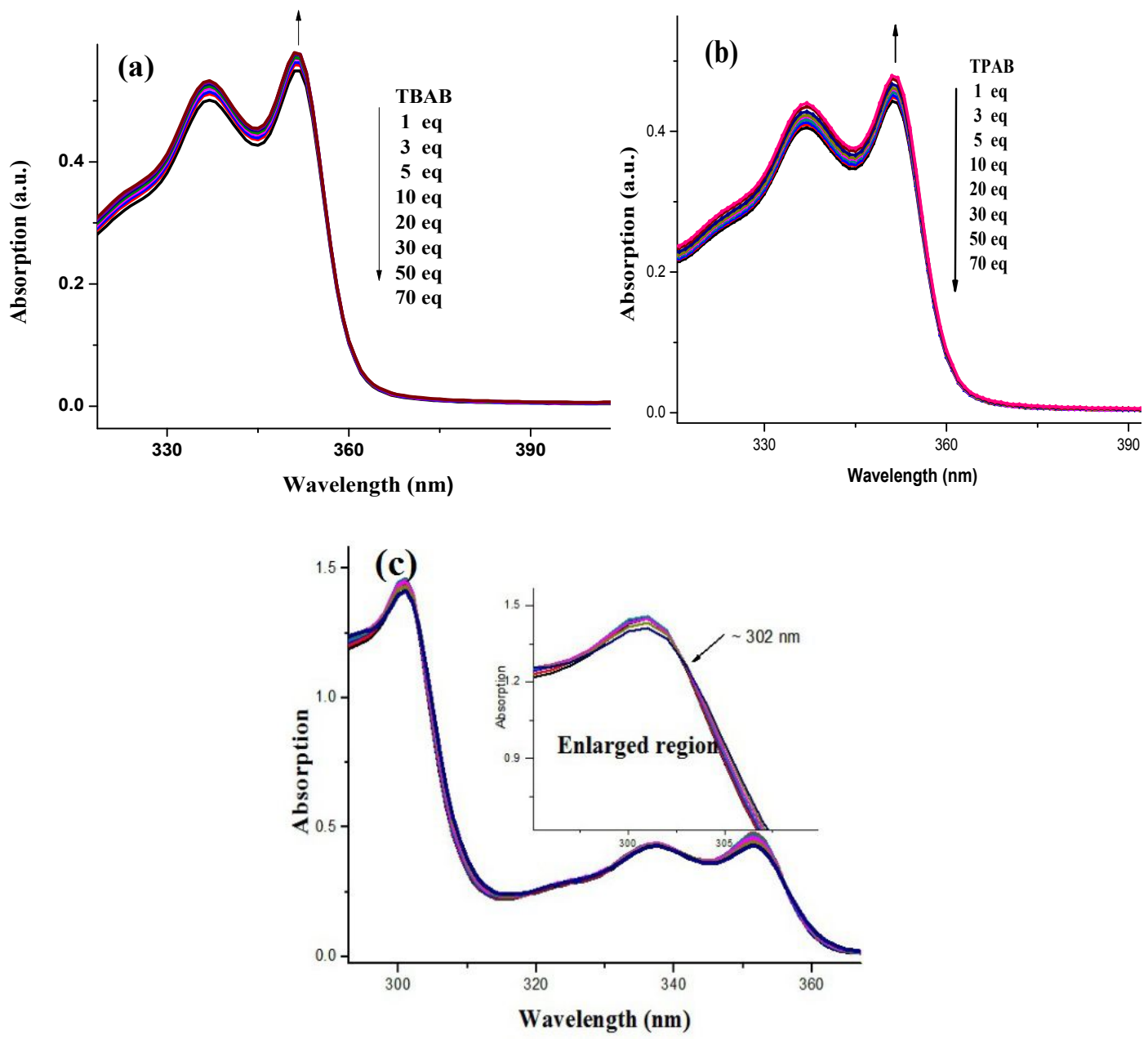

Figure S21. UV-vis spectra of $2(50 \mu \mathrm{M})$ upon addition of (a): TBAB in $\mathrm{CHCl}_{3}$; (b): $\mathrm{TPAB}$ in $\mathrm{CHCl}_{3}$; (c): TEAB in $\mathbf{C H}_{2} \mathbf{C l}_{\mathbf{2}}$

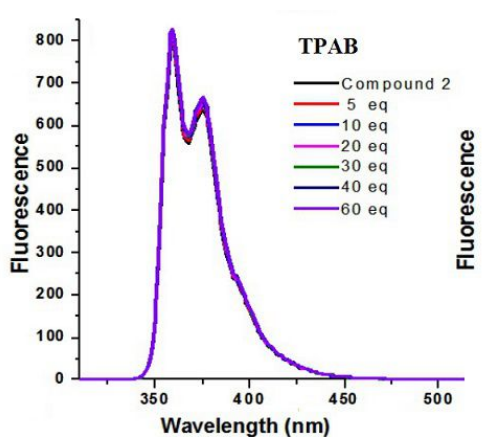

(a)

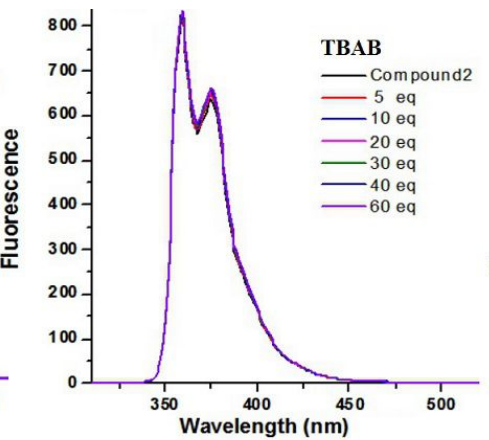

(b)

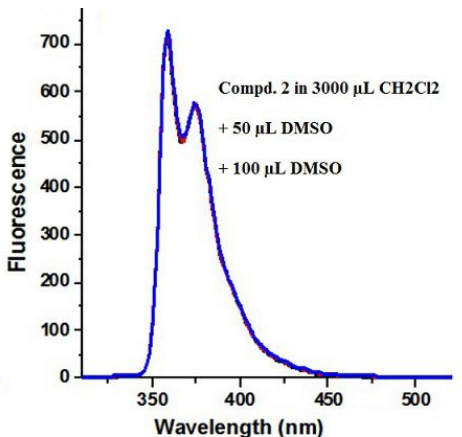

(c)

Figure S22. Fluorescent spectra of $2(30 \mu \mathrm{M})$ upon addition of (a) TPAB; (b) TBAB in $\mathrm{CH}_{2} \mathrm{Cl}_{2}$ at $25{ }^{\circ} \mathrm{C}$; (c) $30 \mu \mathrm{L}$ and $110 \mu \mathrm{L}$ DMSO (Excitation wavelength was $302 \mathrm{~nm}$, which was selected based on the preliminary UV-vis titration of 2 with TEAB in $\mathrm{CH}_{2} \mathrm{Cl}_{2}$ : see Figure $\mathbf{S 2 1}$ (c))

Note: For unknown reasons, fluorescent spectra of 2 are not stable in $\mathrm{CHCl}_{3}$, so that all of its fluorescent spectra were recorded in $\mathrm{CH}_{2} \mathrm{Cl}_{2}$ to make the results reliable. For the sake of solubility, the stock solutions of guests were prepared in DMSO (see details in 1.1 Reagents and analytical methods). It indeed will cause experimental error for accurate $\boldsymbol{K}_{\boldsymbol{a}}$ determination, but our purpose is solely to compare qualitatively the differences of binding affinities of $\mathbf{2}$ with these guests by using this technique, we thought that it could do the work. Besides, 
for the fluorescent titrations of all the guests, the finial concentration of DMSO in the cuvette (in the end of the titration) is no more than 3.6\%, and this contents of $\mathrm{DMSO}$ in $\mathrm{CH}_{2} \mathrm{Cl}_{2}$ did not affect the fluorescence of 2 , which could be seen from Figure S22(d).

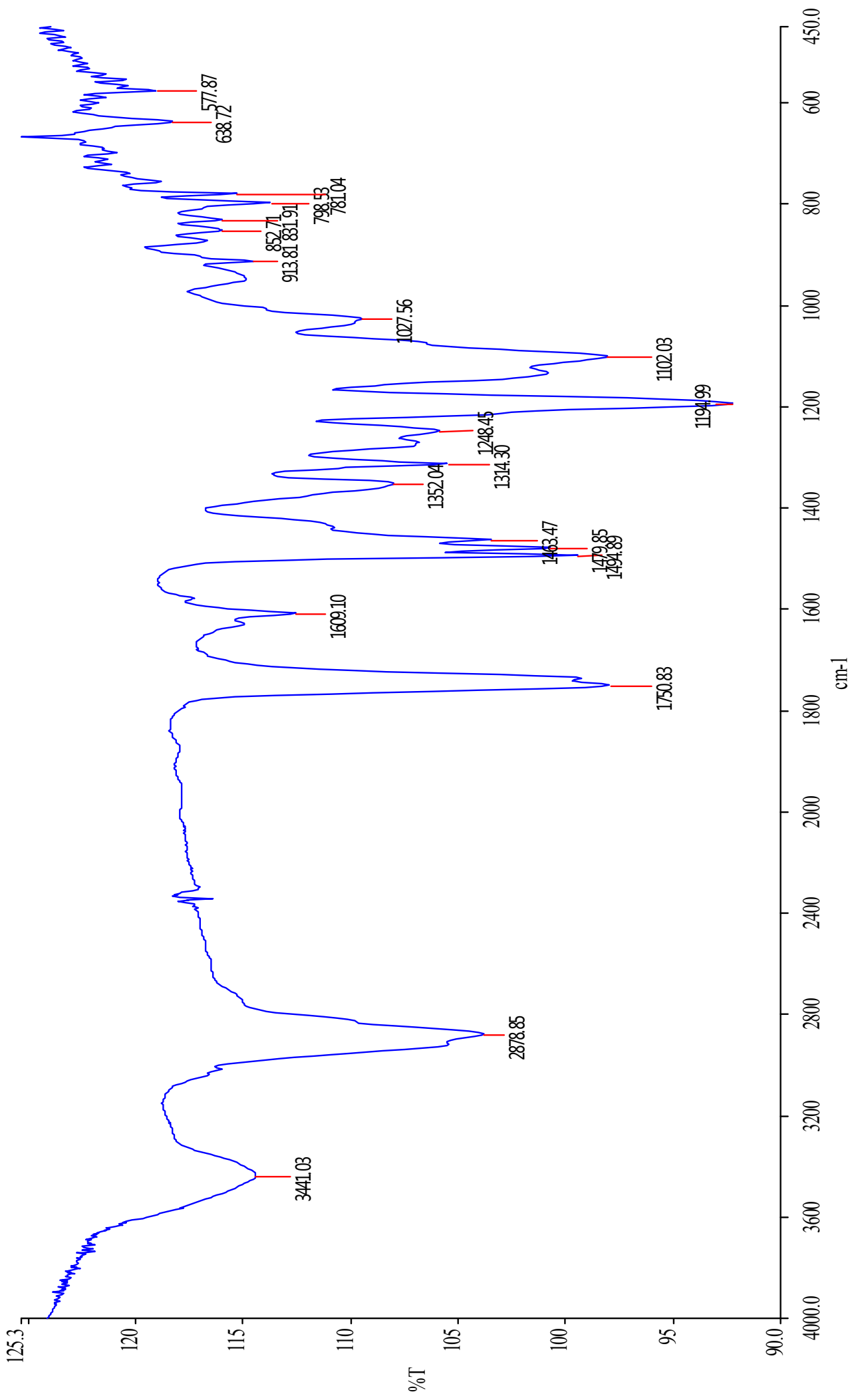

Figure S23. IR spectrum of 2 


\section{2D NMR Spectra of 2 in the Absence and Presence of Guest}

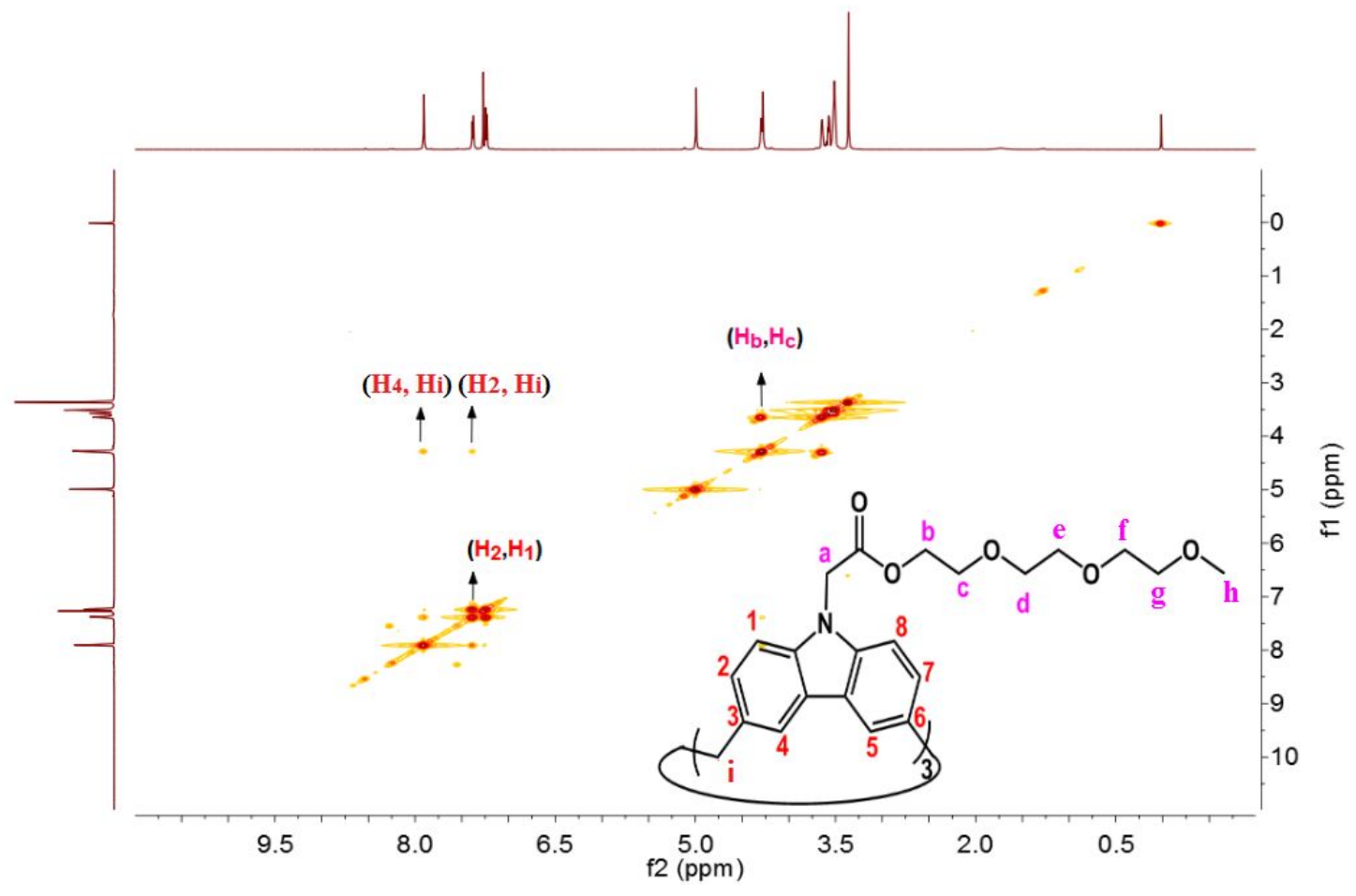

Figure S24. ${ }^{1} \mathrm{H}-{ }^{1} \mathrm{H}$ COSY spectrum of $\mathbf{2}$ in $\mathrm{CDCl}_{3}$ at $25{ }^{\circ} \mathrm{C}$

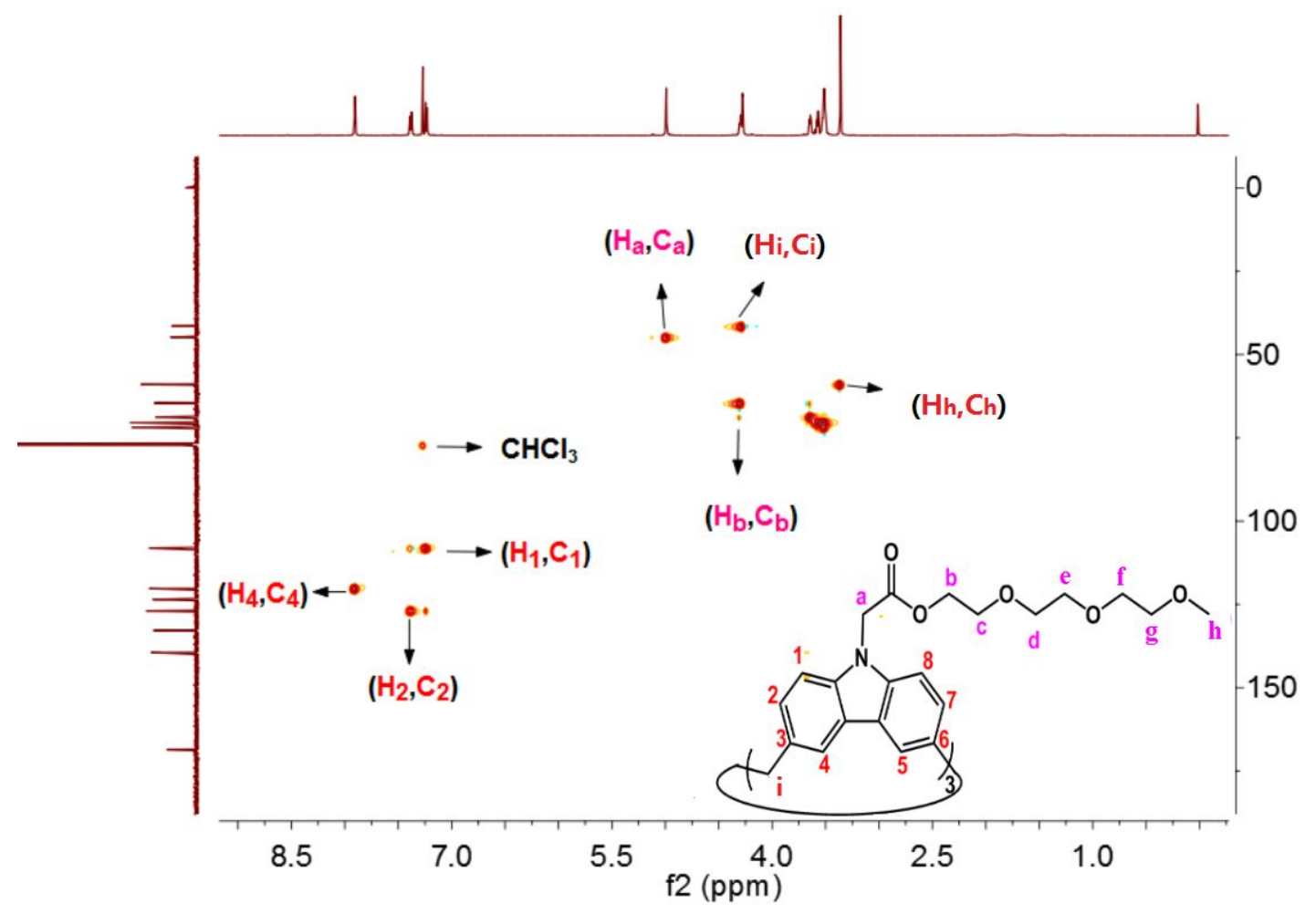

Figure S25. HSQC spectrum of 2 in $\mathrm{CDCl}_{3}$ at $25^{\circ} \mathrm{C}$ 


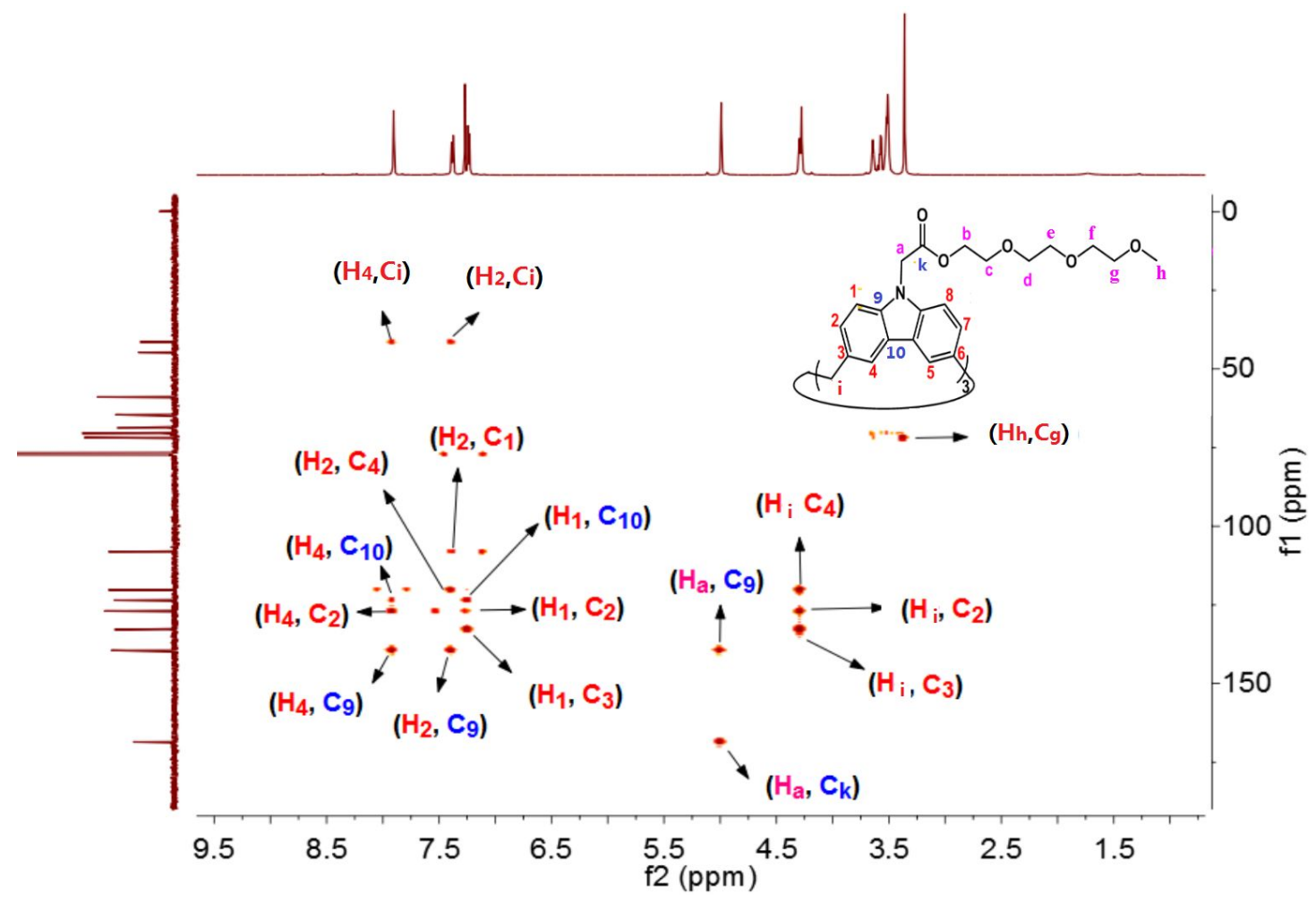

Figure S26. $\mathrm{HMBC}$ spectrum of $\mathbf{2}$ in $\mathrm{CDCl}_{3}$ at $25^{\circ} \mathrm{C}$

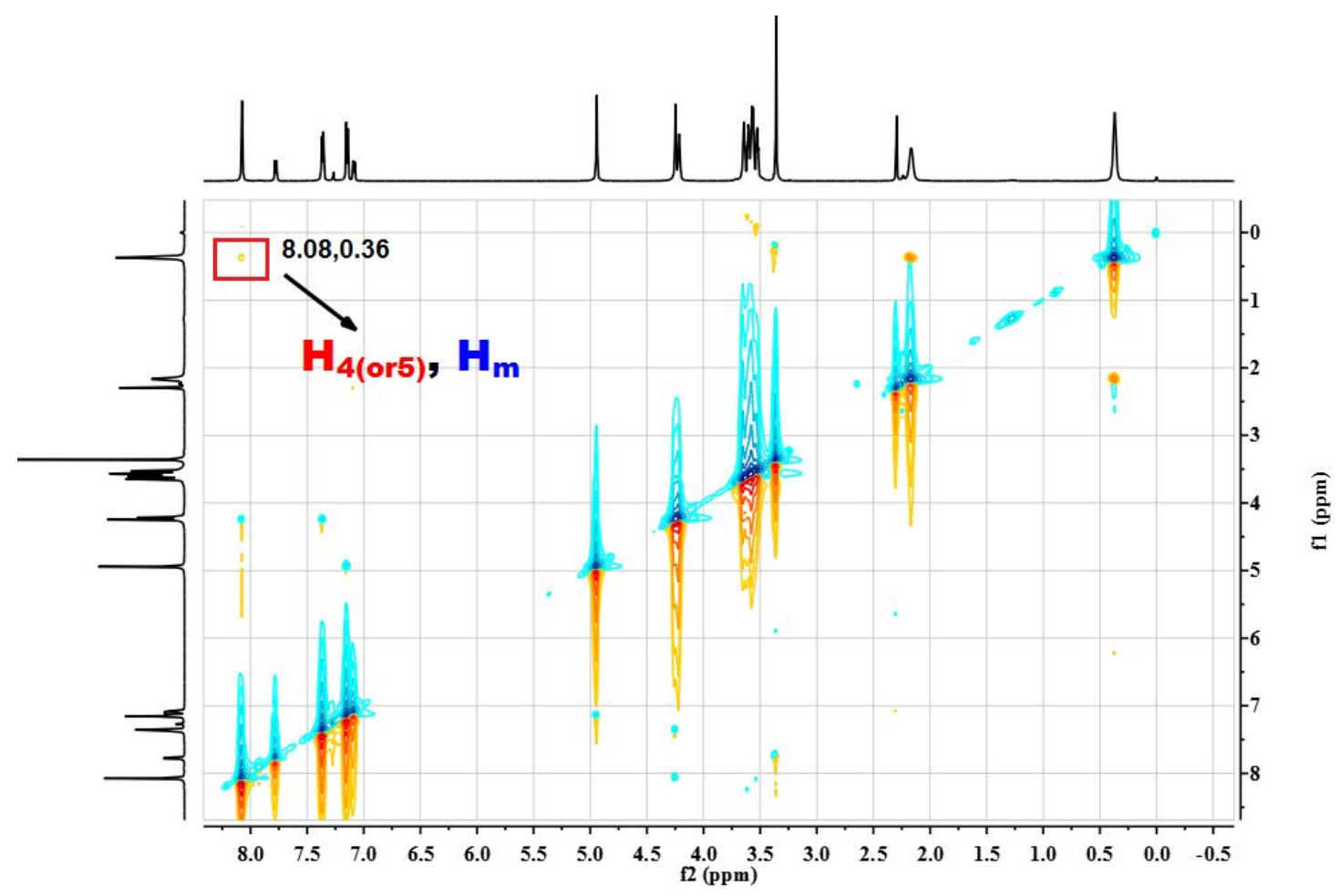

(a) 


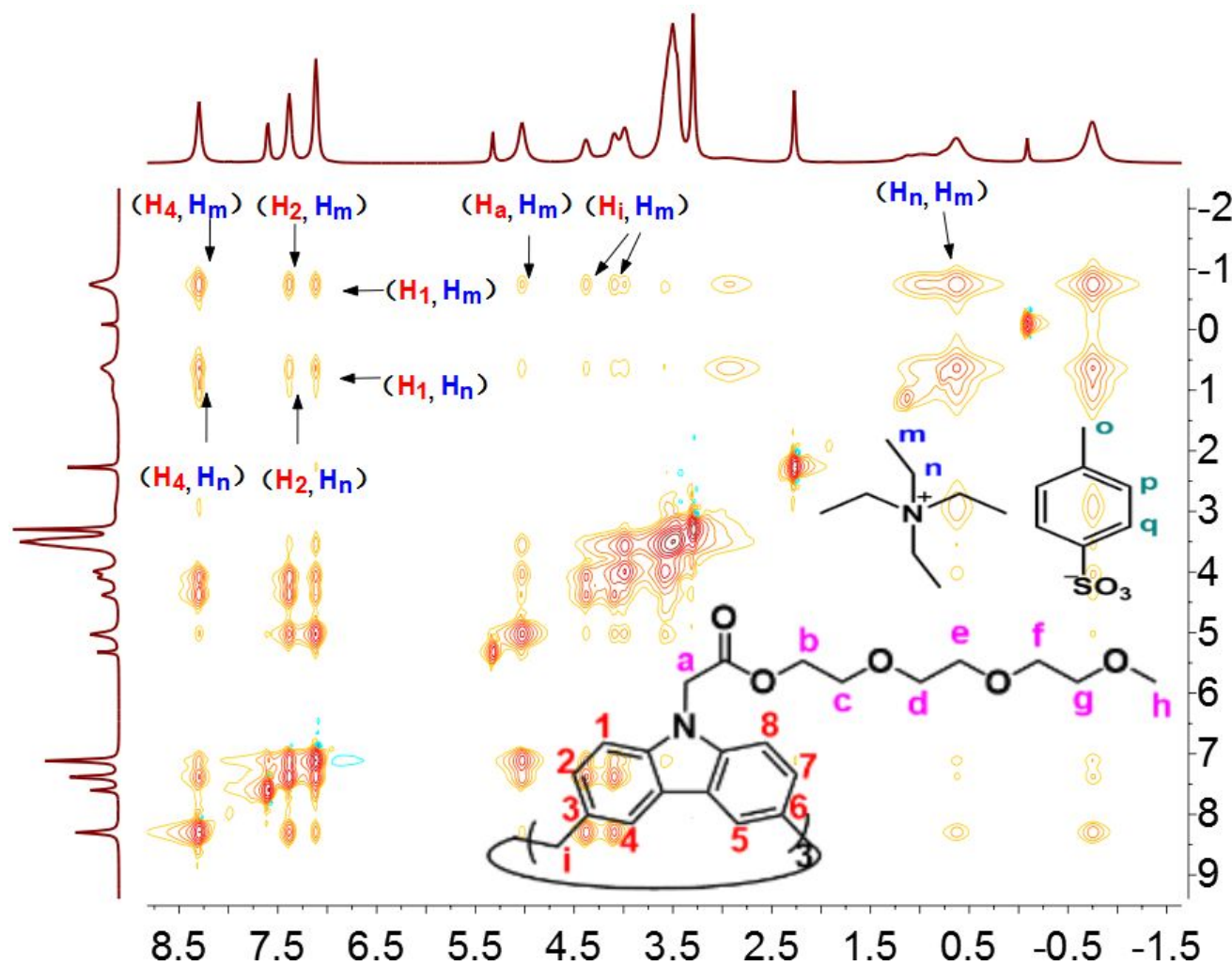

(b)

Figure S27. 2D NOESY spectrum of an equimolar mixture of $[\mathbf{2}+\mathbf{T E A}]$ in $\mathrm{CDCl}_{3} / \mathrm{CD}_{2} \mathrm{Cl}_{2}$

(a) : at $25^{\circ} \mathrm{C}$; (b): at $-92^{\circ} \mathrm{C}$;

5.Job Plot and HRMS Spectrum of 1:1 [2]/[TEA] Complex

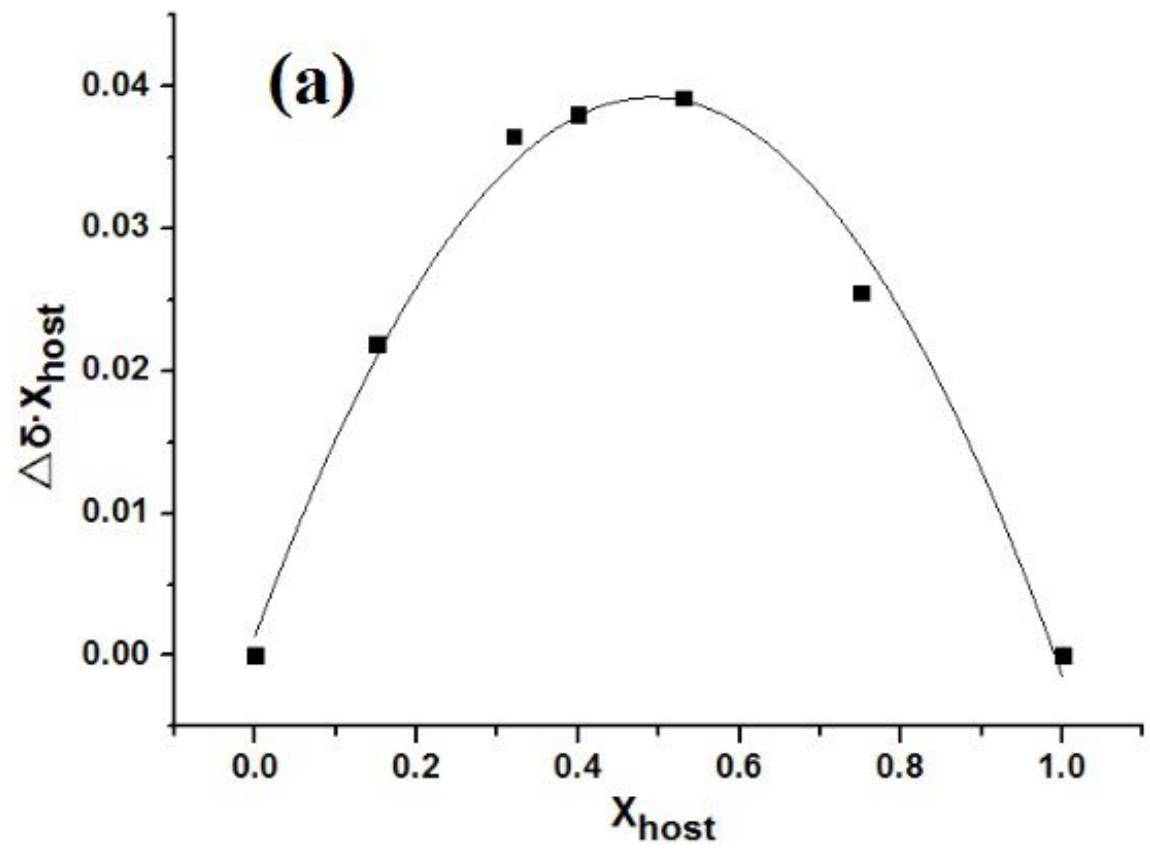


(b)

\section{Mass Spectrum Molecular Formula Report}

Analysis Info

Analysis Name Method

Sample Name

D:IDatal20150403CEYANGIYP-zhou-150303.d 20131026 ceyang.m

YP-zhou-150303

Comment
Acquisition Date 4/25/2015 2:03:49 PM

Instrument / Ser\# Bruker Customer

Operator micrOTOF-Q 125

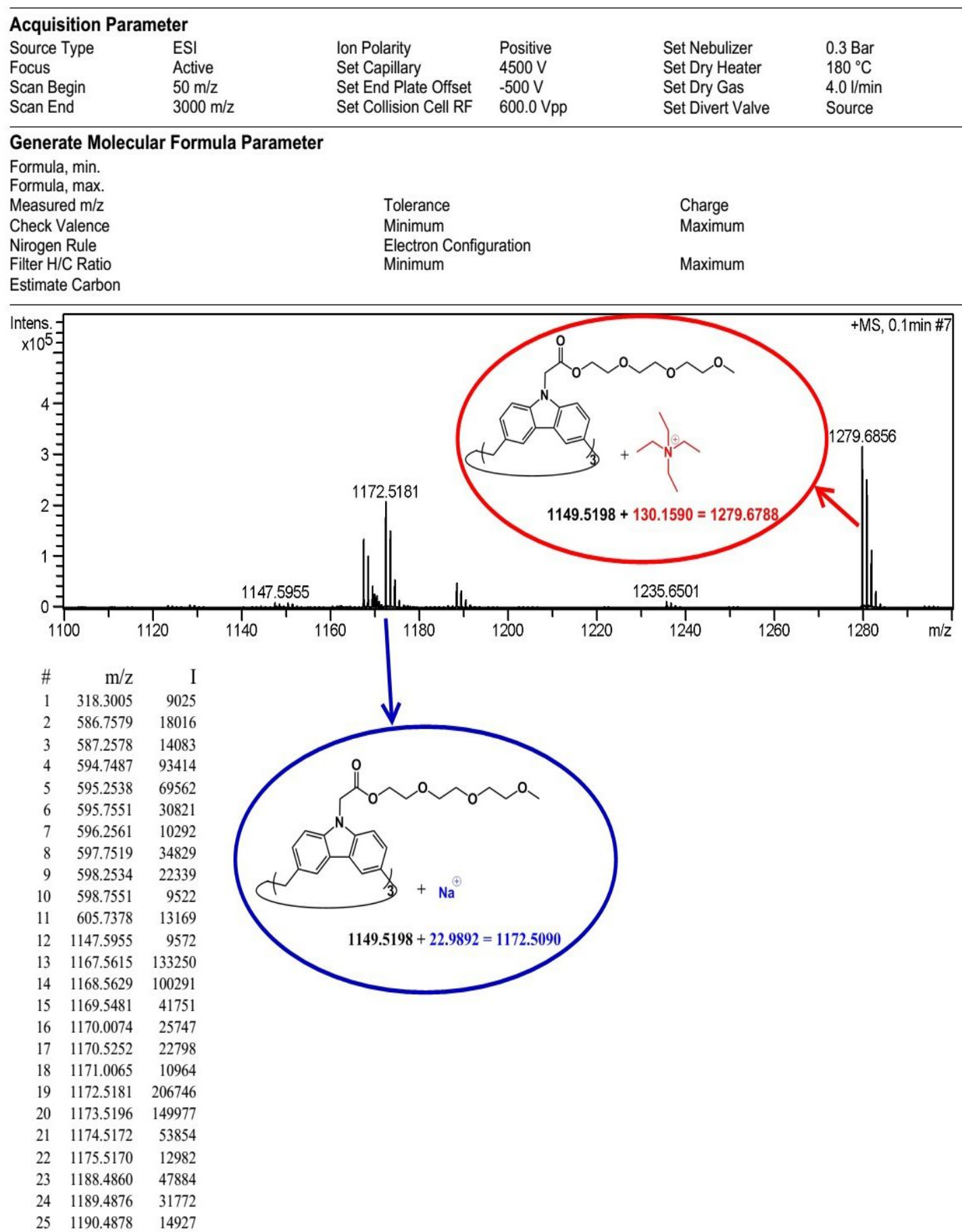


Mass Spectrum Molecular Formula Report

$\begin{array}{rrr}\# & \mathrm{~m} / \mathrm{z} & \mathrm{I} \\ 26 & 1235.6501 & 10866 \\ 27 & 1279.6856 & 315428 \\ 28 & 1280.6885 & 250626 \\ 29 & 1281.6910 & 111628 \\ 30 & 1282.6863 & 31462\end{array}$

Figure S28 (a) Job plot operated by ${ }^{1} \mathrm{HNMR}$; (b) HRMS spectrum of an equimolar mixture of [2+TEA] 


\section{1D ${ }^{1}$ HNMR Titration Spectra}

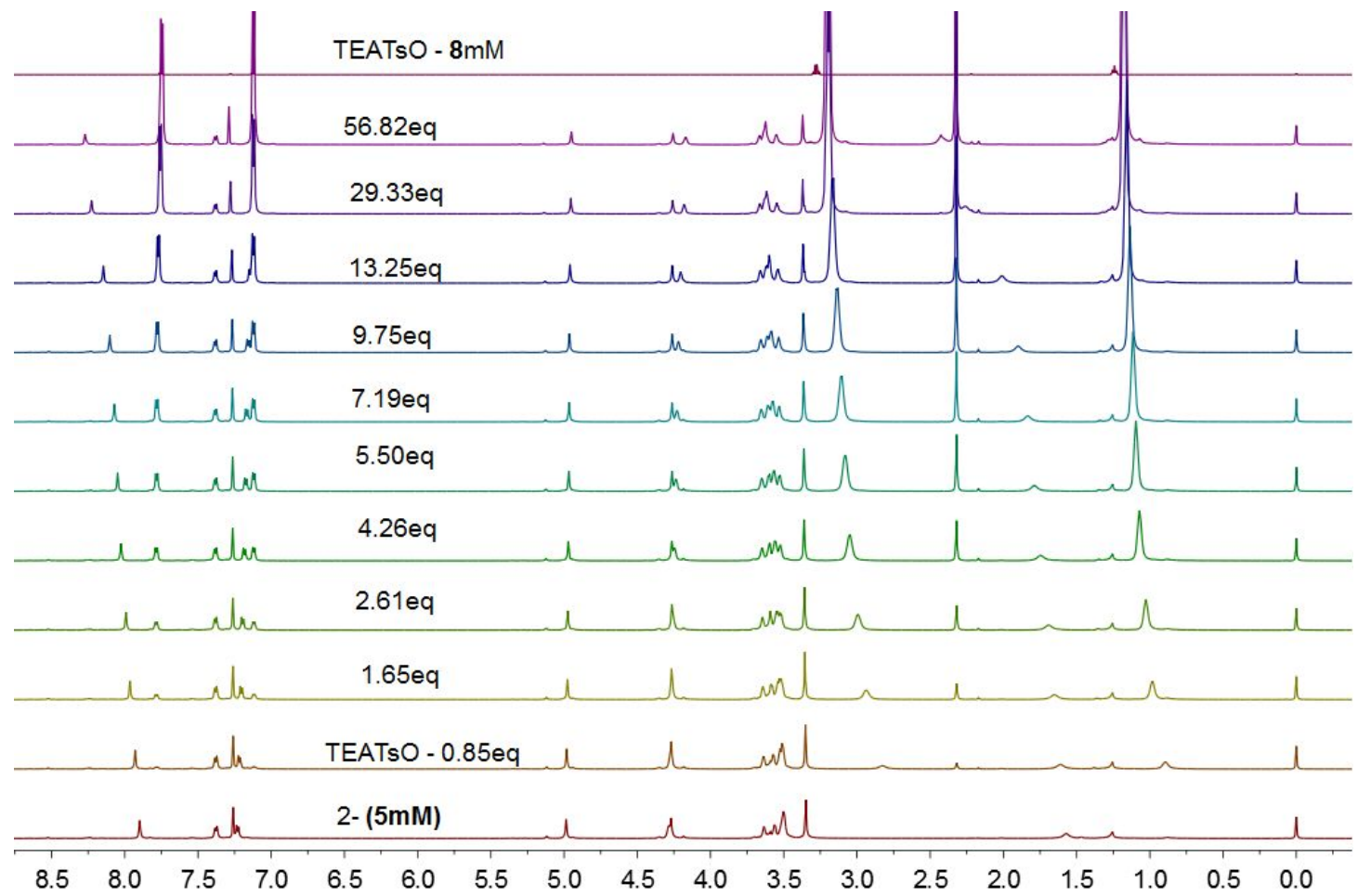

Figure S29. ${ }^{1} \mathrm{HNMR}$ spectra of $2(5 \mathrm{mM})$ upon addition of TEATsO in $\mathrm{CDCl}_{3}$ at $25{ }^{\circ} \mathrm{C}$

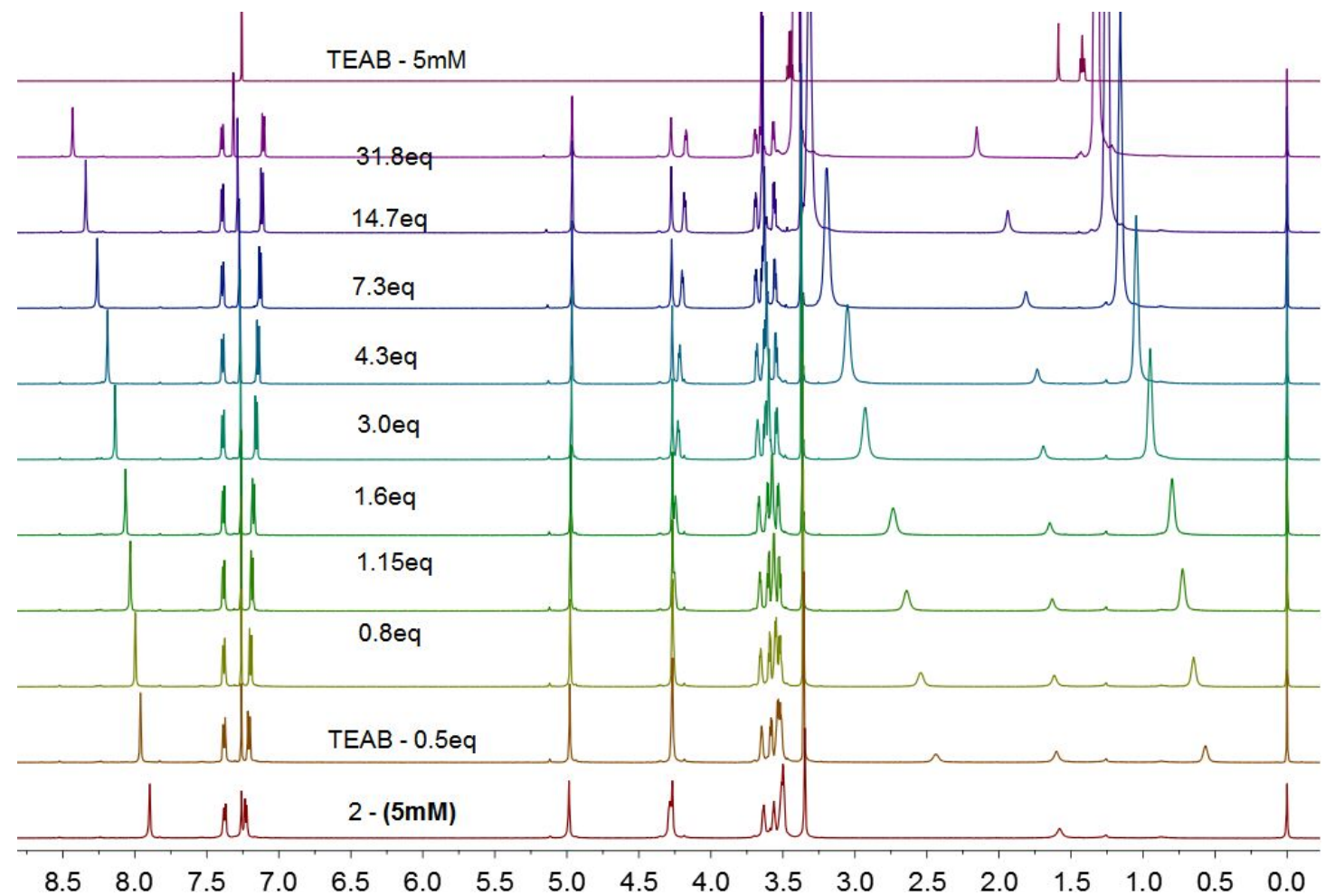

Figure S30. ${ }^{1} \mathrm{HNMR}$ spectra of $2(5 \mathrm{mM})$ upon addition of TEAB in $\mathrm{CDCl}_{3}$ at $25{ }^{\circ} \mathrm{C}$ 


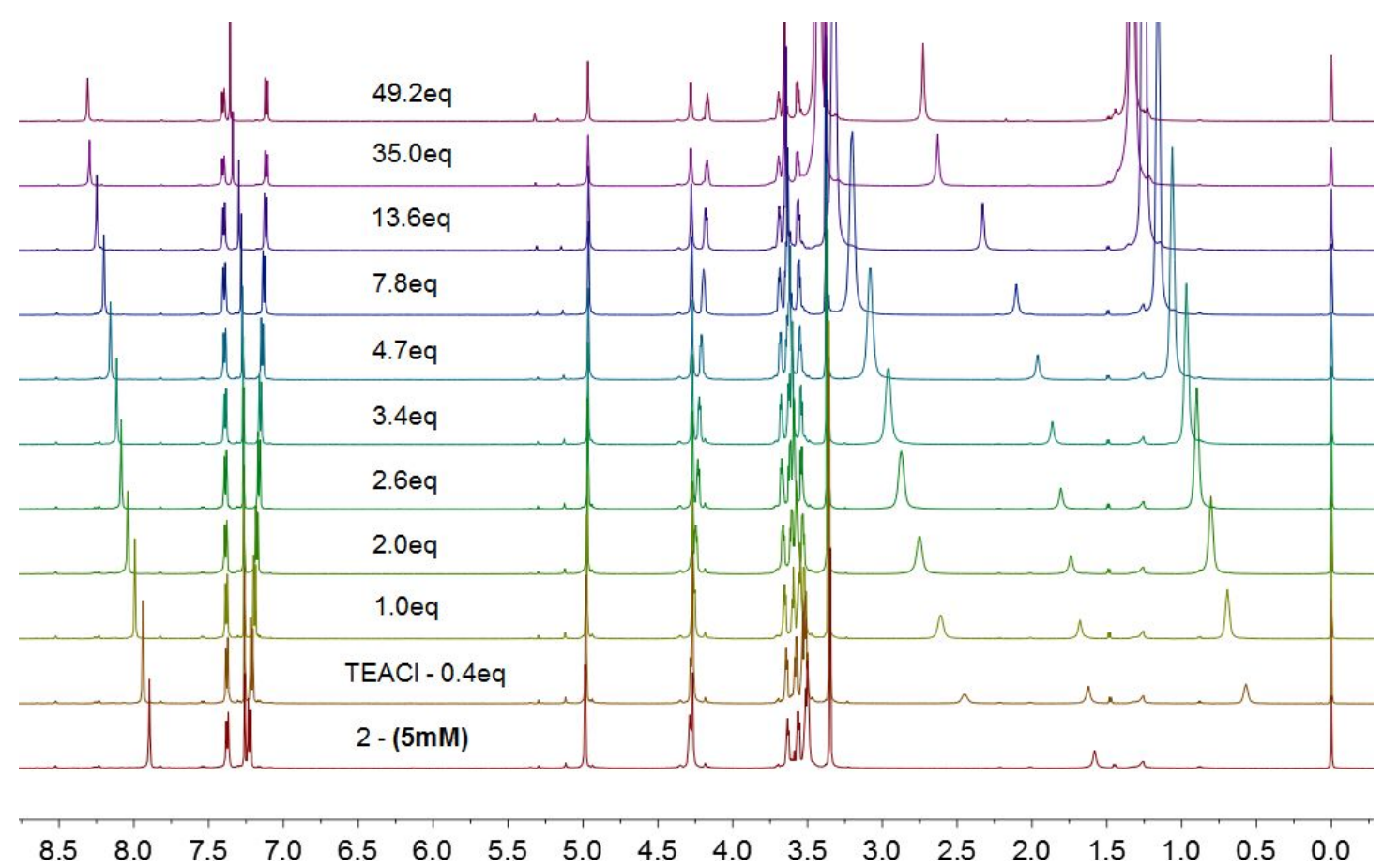

Figure S31. ${ }^{1} \mathrm{HNMR}$ spectra of $\mathbf{2}(5 \mathrm{mM})$ upon addition of $\mathrm{TEACl}$ in $\mathrm{CDCl}_{3}$ at $25{ }^{\circ} \mathrm{C}$

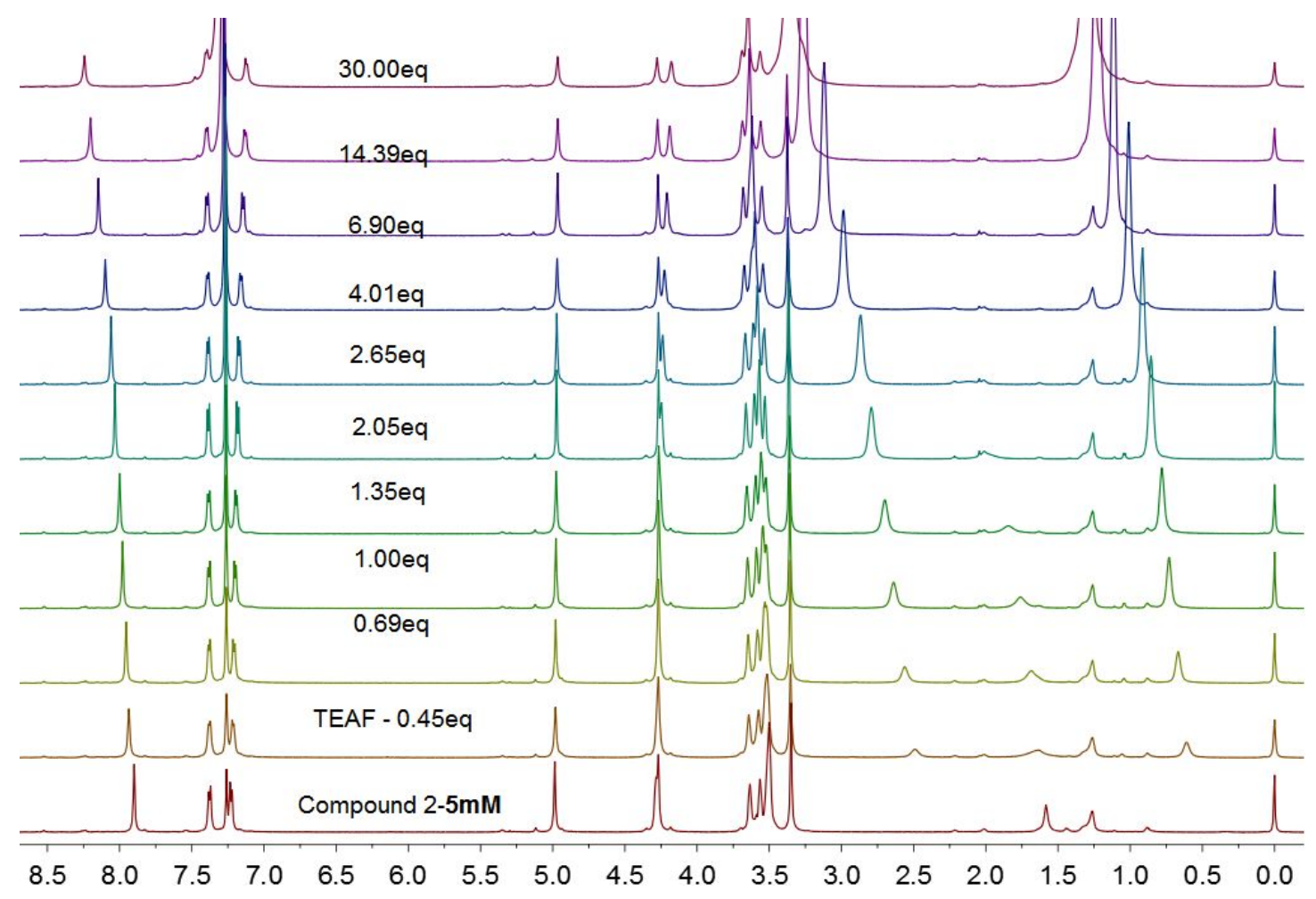

Figure S32. ${ }^{1} \mathrm{HNMR}$ spectra of $\mathbf{2}(5 \mathrm{mM})$ upon addition of TEAF in $\mathrm{CDCl}_{3}$ at $25{ }^{\circ} \mathrm{C}$ 


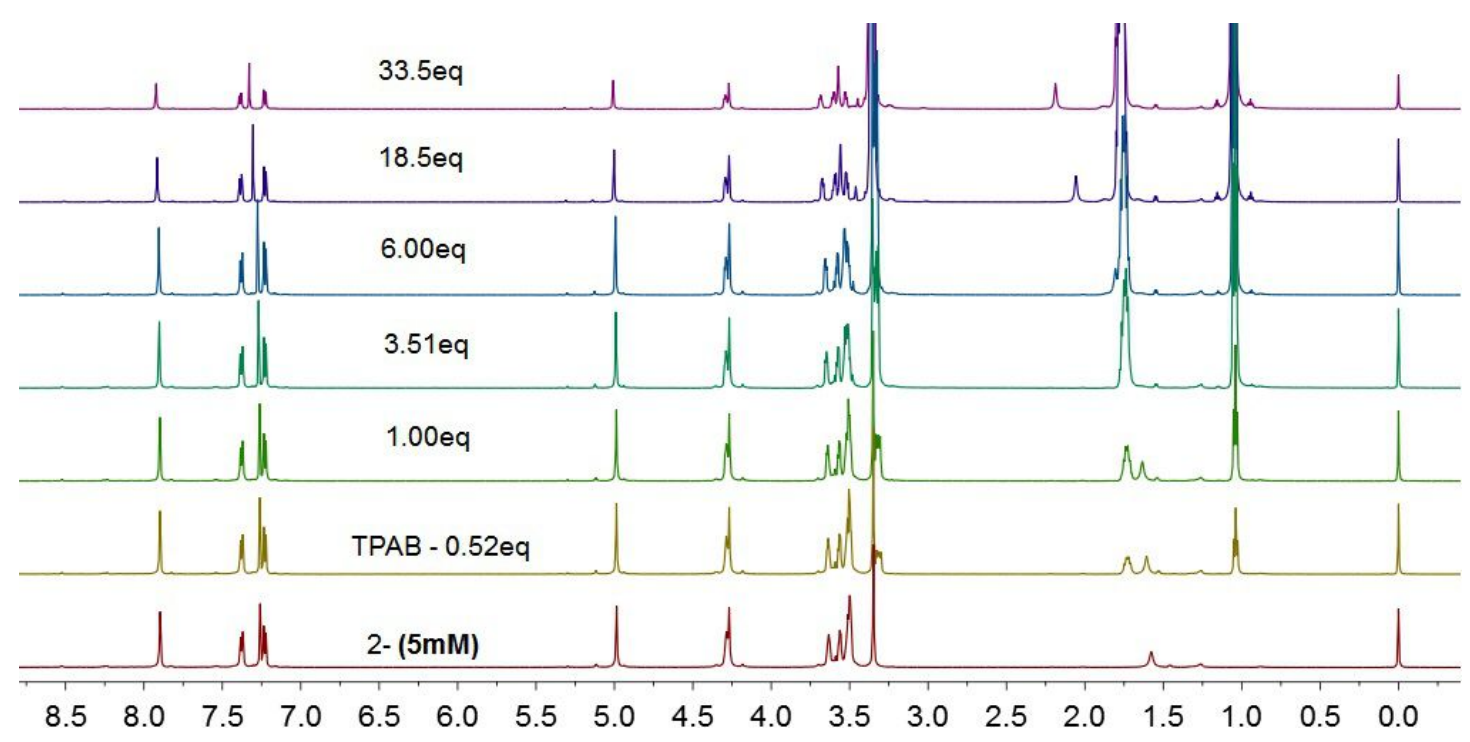

Figure S33. ${ }^{1} \mathrm{HNMR}$ spectra of $2(5 \mathrm{mM})$ upon addition of TPAB in $\mathrm{CDCl}_{3}$ at $25{ }^{\circ} \mathrm{C}$
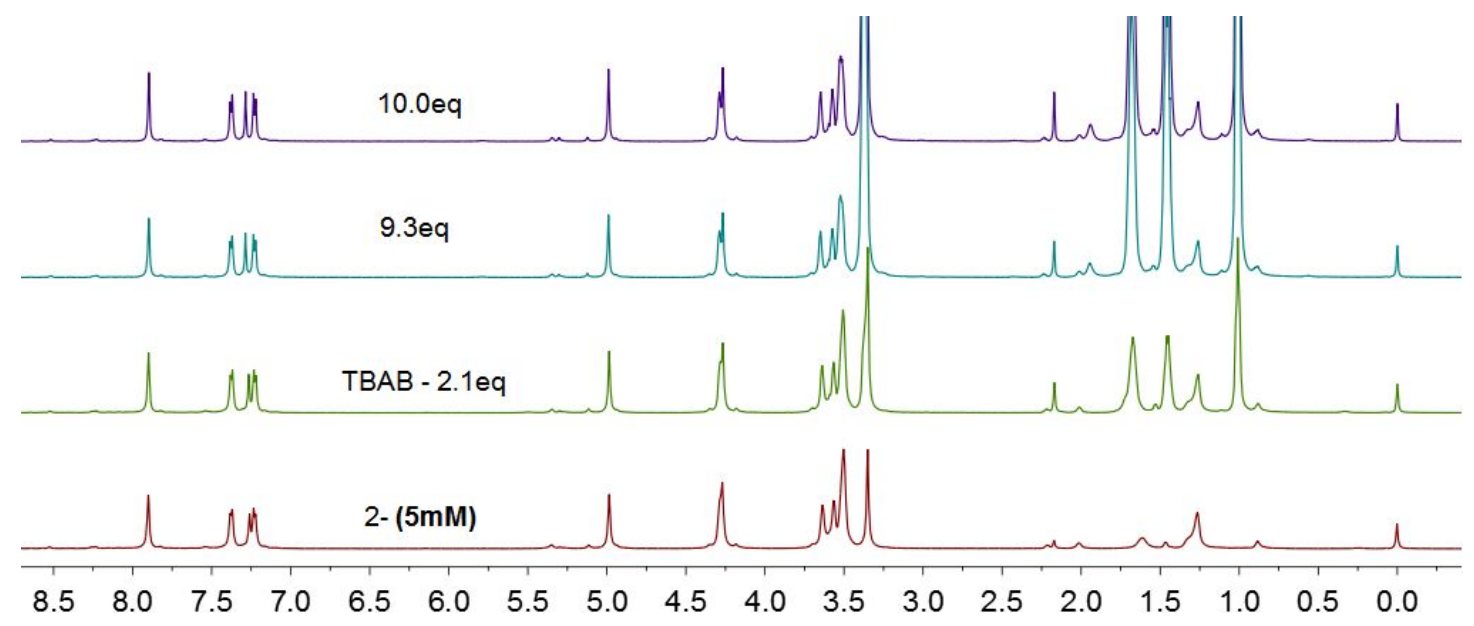

Figure S34. ${ }^{1} \mathrm{HNMR}$ spectra of $2(5 \mathrm{mM})$ upon addition of $\mathrm{TBAB}$ in $\mathrm{CDCl}_{3}$ at $25{ }^{\circ} \mathrm{C}$ 


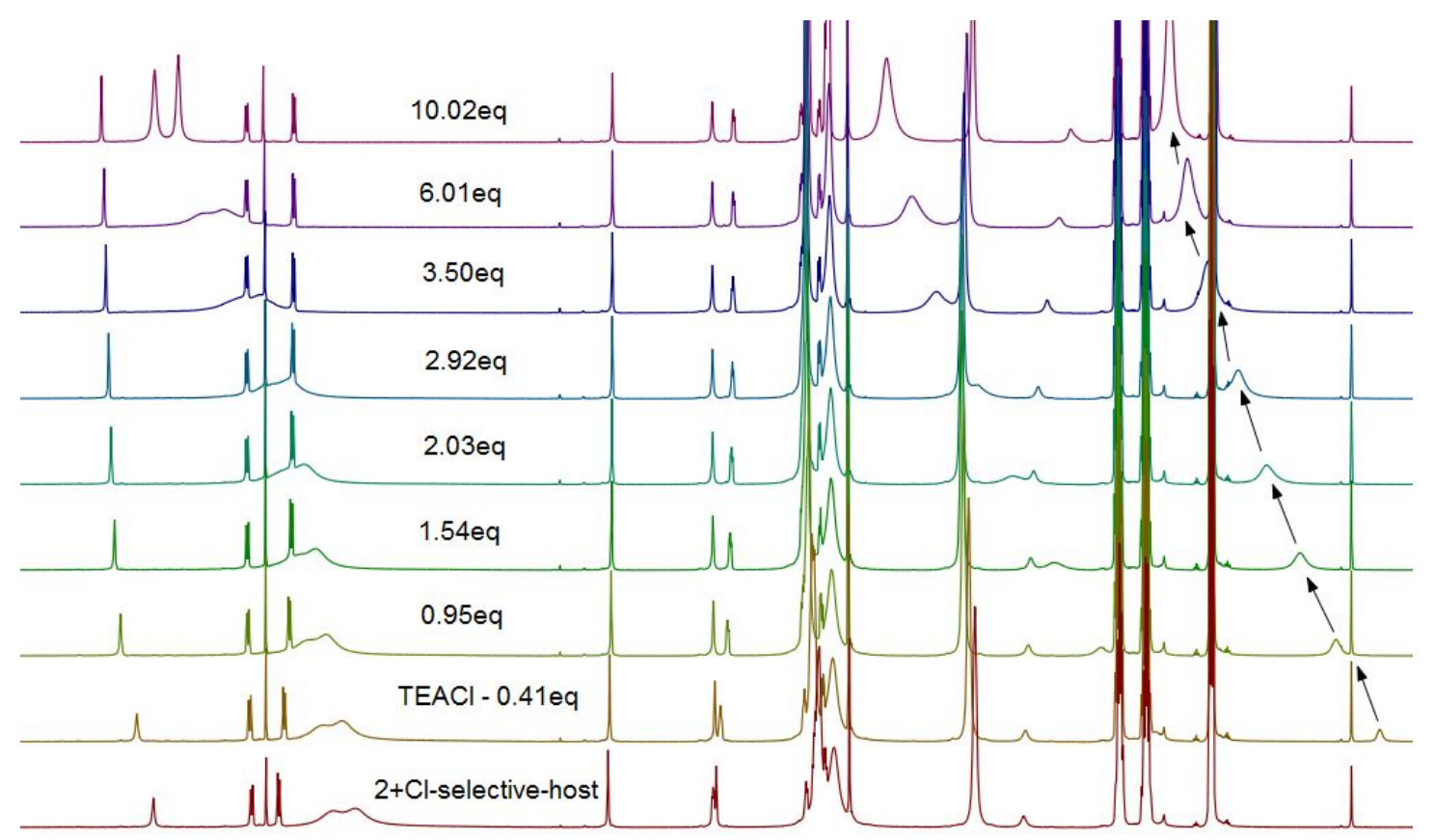

$\begin{array}{llllllllllllllllll}8.5 & 8.0 & 7.5 & 7.0 & 6.5 & 6.0 & 5.5 & 5.0 & \begin{array}{l}4.5 \\ \mathrm{f} 1\end{array}(\mathrm{ppm}) \\ 4.0 & 3.5 & 3.0 & 2.5 & 2.0 & 1.5 & 1.0 & 0.5 & 0.0\end{array}$

Figure S35. ${ }^{1} \mathrm{HNMR}$ spectra of $2(5 \mathrm{mM})$ upon addition of TEACl in the prescence of $\mathrm{Cl}^{-}$selective host (5 $\mathrm{mM})$ in $\mathrm{CDCl}_{3}$ at $25^{\circ} \mathrm{C}$

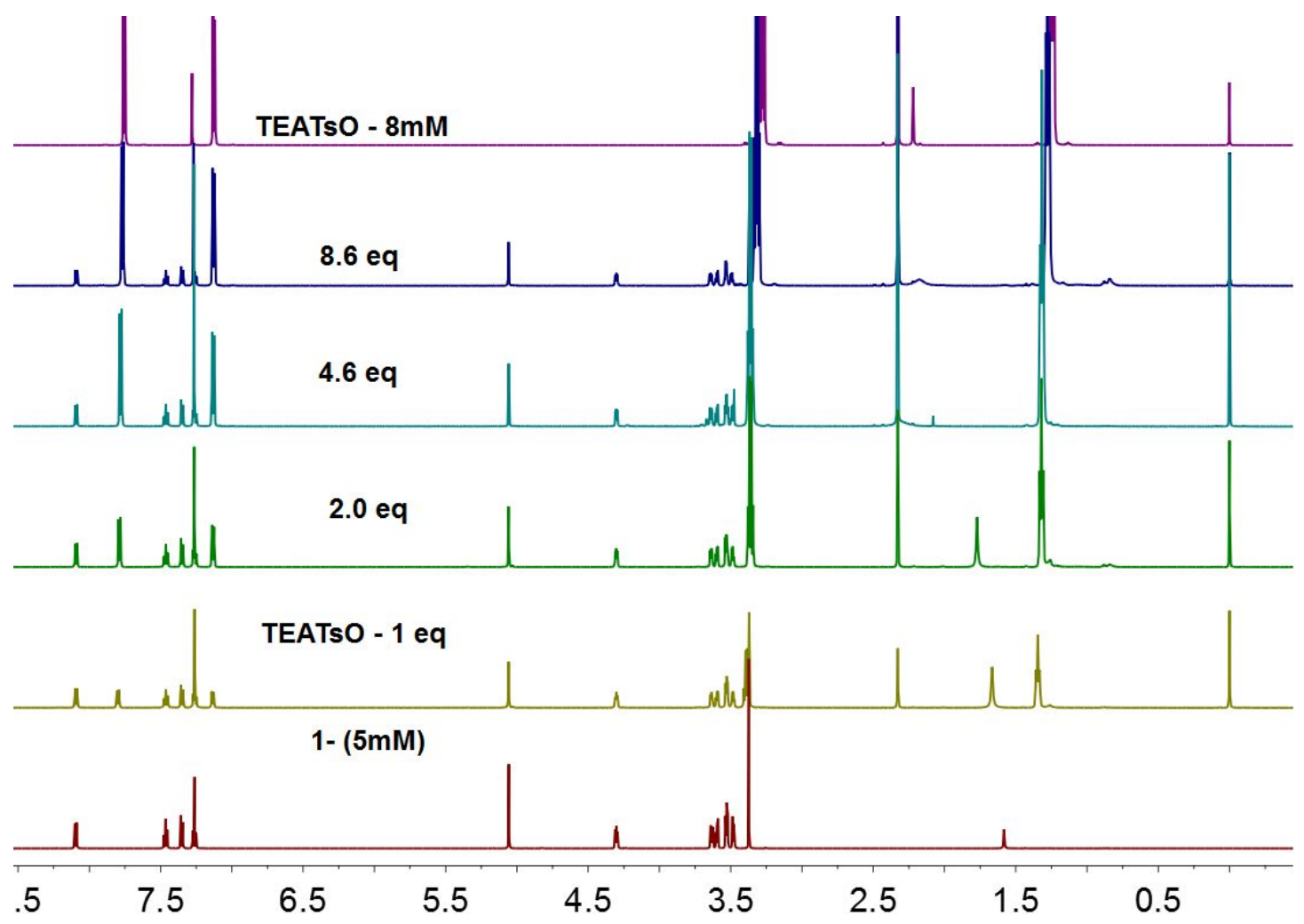

Figure S36. ${ }^{1} \mathrm{HNMR}$ spectra of the control compound $\mathbf{1}(5 \mathrm{mM})$ upon addition of TEATsO in $\mathrm{CDCl}_{3}$ at $25{ }^{\circ} \mathrm{C}$ 


\section{Determination of Association Constants}

\section{Host-Guest binding constant:}

$\boldsymbol{K}_{\boldsymbol{a}}$ was determined by a nonlinear least-squares analysis of $\boldsymbol{h}$ versus $[\boldsymbol{s}]$ using the following equation for 1:1 stoichiometry binding ${ }^{1:}$

$$
h=\frac{\Delta \delta_{\max } \times K a[s]}{1+K a[s]}
$$

Where [s] is guest concentration, $\boldsymbol{h}$ is $\Delta \delta, \Delta \delta=\delta_{\mathrm{obs}}-\delta_{0}, \Delta \delta_{\max }=\delta_{\max }-\delta_{0}, \delta_{0}$ is the chemical shift of proton 4 (or 5) of the host $\mathbf{2}$ in the absence of the guest.

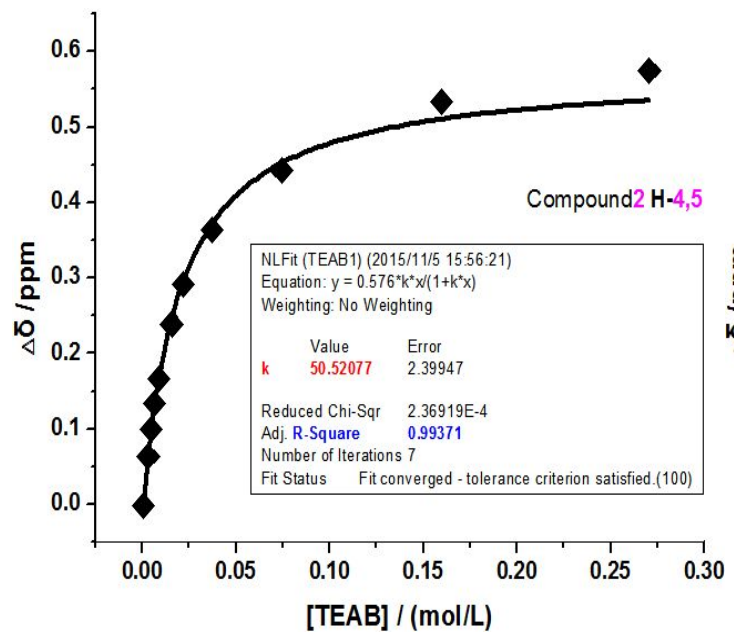

(a)

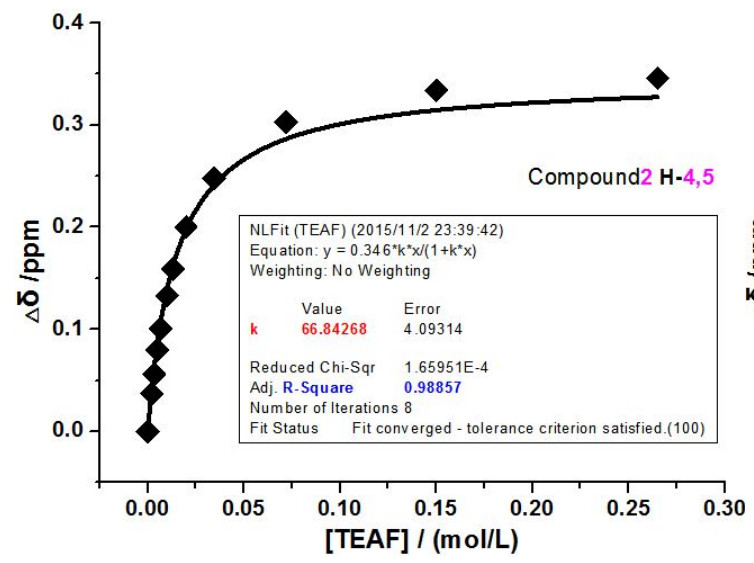

(c)

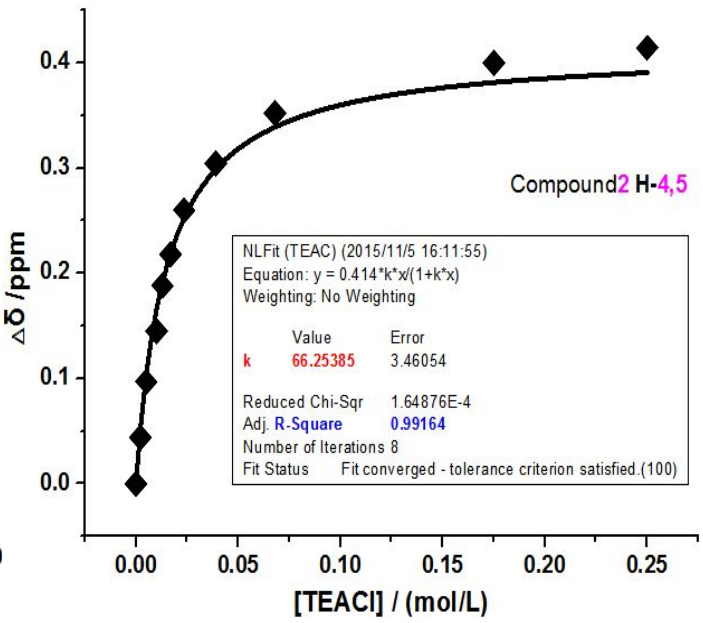

(b)

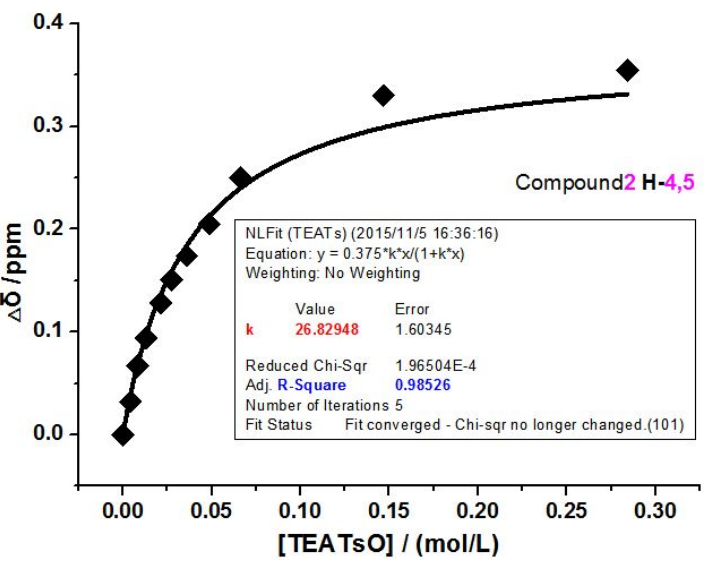

(d) 


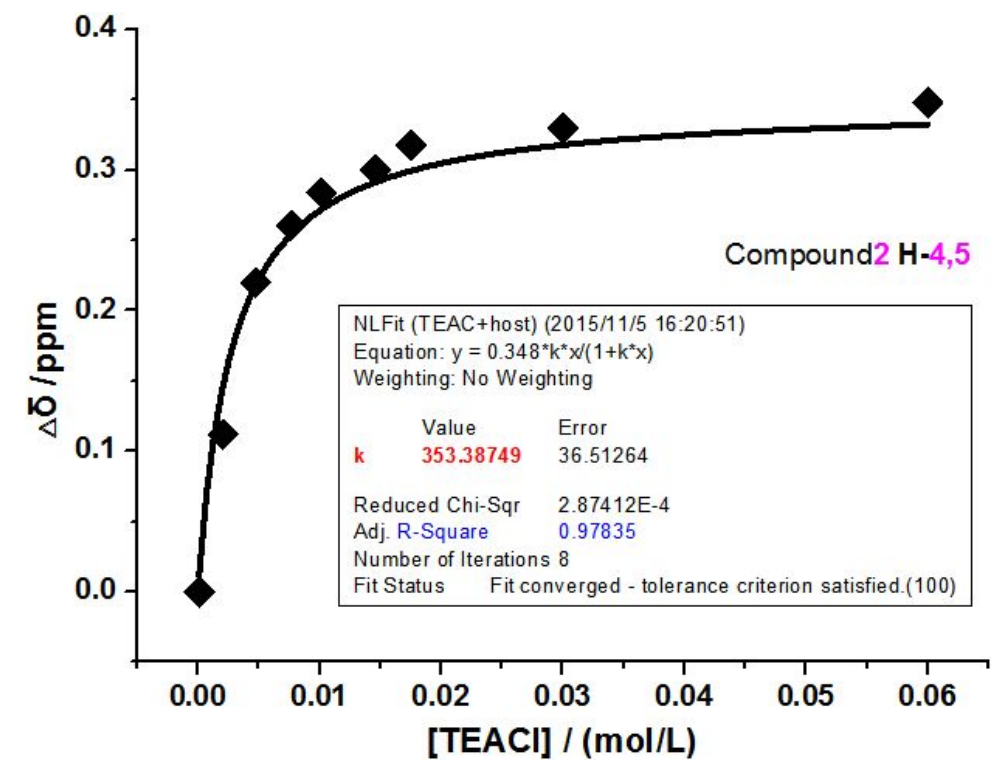

(e) Dual hosts

Figure S37. Fitted curves using the changes of chemical shifts of H4(5) in ${ }^{1} \mathrm{HNMR}$ spectra of 2 upon addition of (a): TEAB; (b): TEACl; (c): TEAF; (d) TEATsO; (e) Fitted curve using the changes of chemical shifts of H4(5) in ${ }^{1} \mathrm{HNMR}$ spectra of dual hosts (2+chloride anion ligand,1:1) upon addition of TEACl in $\mathrm{CDCl}_{3}$ at $25{ }^{\circ} \mathrm{C}$

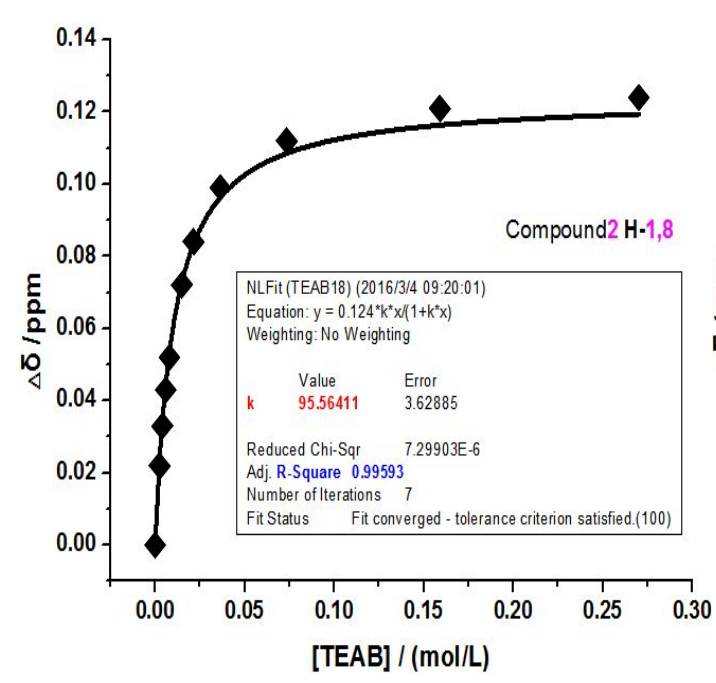

(a)

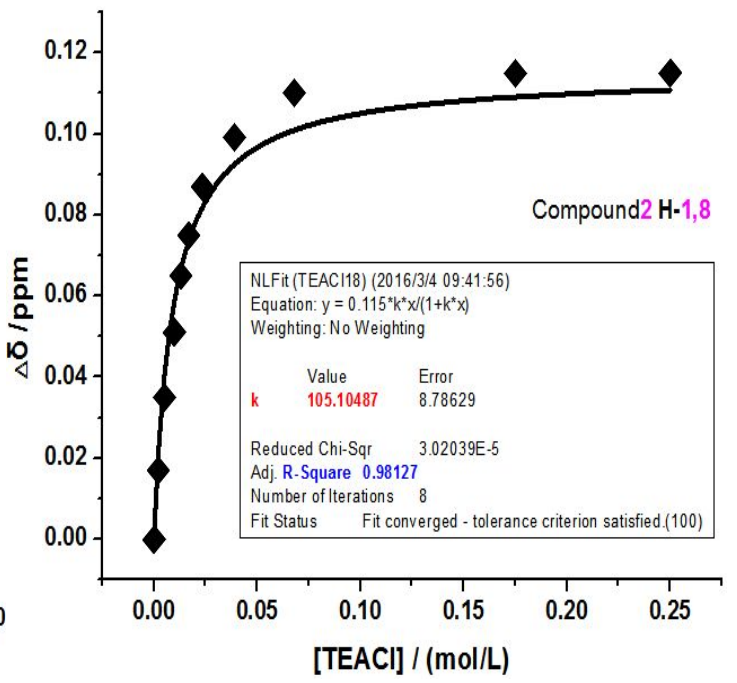

(b) 


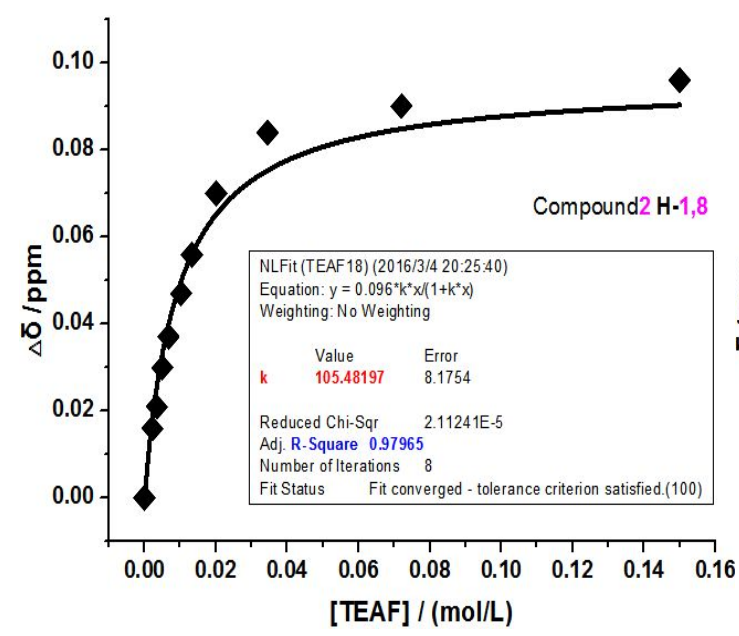

(c)

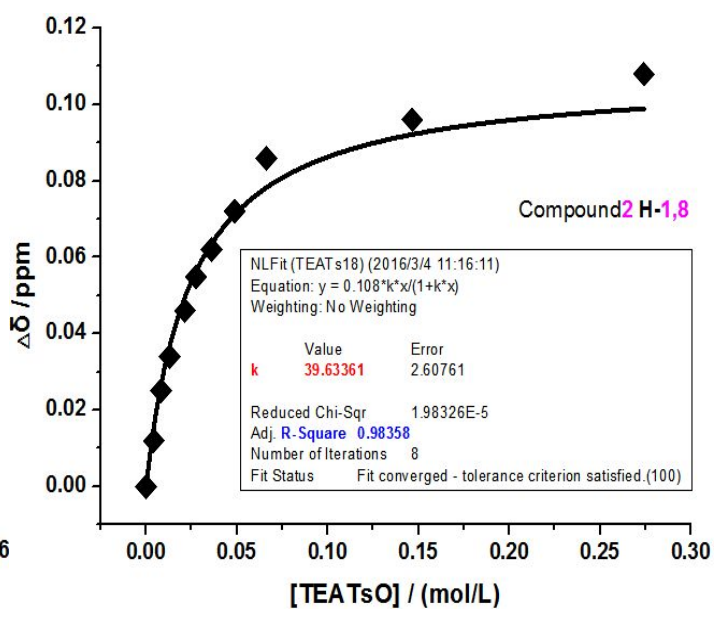

(d)

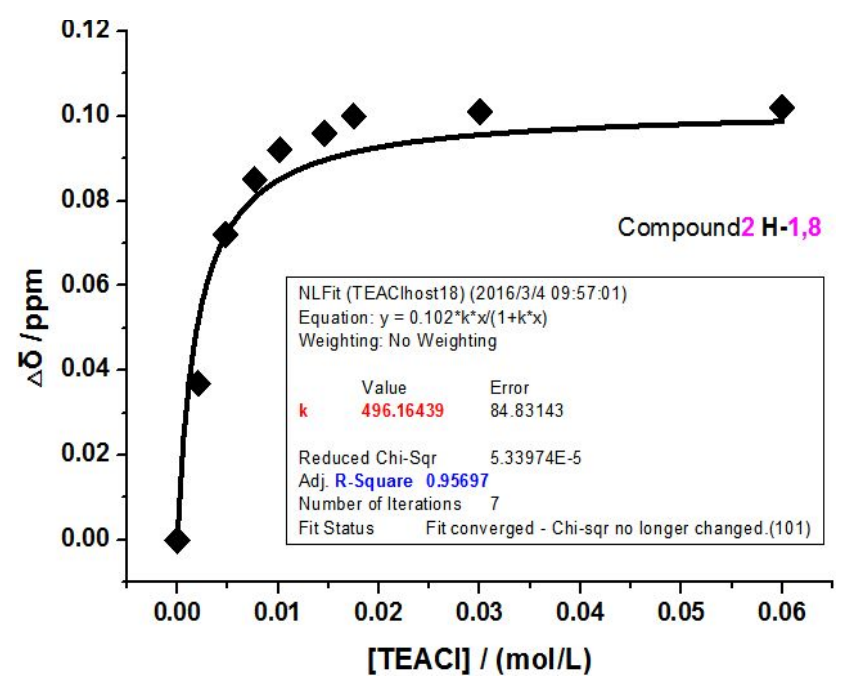

(e) Dual hosts

Figure S38. Fitted curves using the changes of chemical shifts of H1(8) in ${ }^{1} \mathrm{HNMR}$ spectra of 2 upon addition of (a): TEAB; (b): TEACl; (c): TEAF; (d) TEATsO; (e) Fitted curve using the changes of chemical shifts of H4(5) in ${ }^{1} \mathrm{HNMR}$ spectra of dual hosts (2+chloride anion ligand,1:1) upon addition of $\mathrm{TEACl}$ in $\mathrm{CDCl}_{3}$ at $25{ }^{\circ} \mathrm{C}$

Table S1 Association constants of 2 binding with various guests in $\mathrm{CDCl}_{3}$

\begin{tabular}{cccc}
\hline & $K_{a}(\mathrm{E})\left(\mathrm{M}^{-1}\right)$ & $-\Delta \mathrm{G}(\mathrm{kJ} / \mathrm{mol})$ & $\mathrm{R}^{2}$ \\
\hline TEAB & $95.6(3.6)$ & 11.3 & 0.99 \\
TEACl & $105.1(8.8)$ & 11.5 & 0.98 \\
TEACl/dual hosts & $496.2(84.8)$ & 15.4 & 0.96 \\
TEAF & $105.5(8.2)$ & 11.5 & 0.98 \\
TEATsO & $39.6(2.6)$ & 9.1 & 0.98 \\
TPAB & --- & --- & --- \\
TBAB & --- & --- & --- \\
\hline
\end{tabular}

Note: E means the standard errors of the nonlinear least-squares fitting of the titration curves in Figure S36;

“-” means no binding; - $\Delta G$ was calculated based on Van 't Hoff isotherm equation: $\Delta G=-R T \operatorname{TnK}$; These data were calculated by fitting the changes of the chemical shift of H1(or8) 


\section{Molecular Models}

Conformation analyses of both $\mathbf{2}$ and its complex with TEA were optimized by means of the computer program SPARTAN'14 for windows (V1.1.4, Wavefunction Inc. 18401 Von Karman Avenue, Suite 370 Irvine, CA 92612) on a PC equip with Pentium IV (RAM: 4G). The optimized moiety of $\mathbf{2}$ was selected based on the ${ }^{1} \mathrm{HNMR}$ titration results, the non-recognition-involved moieties were omitted for the sake of both clarity and calculation expense.

Following the methods ${ }^{2}$, conformation search of free $\mathbf{2}$ was carried out using Molecular Mechanics Force Field (MMFF) to give a few optimized low-energy geometries of 2. Figure S39 listed the representative one conformation with the lowest energy.

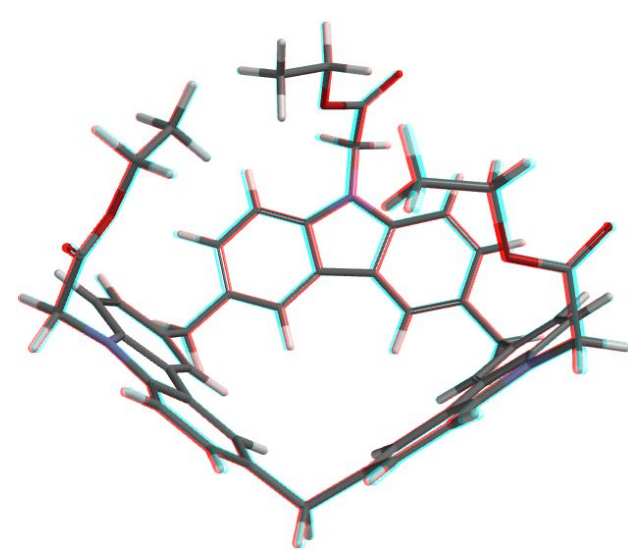

Side view

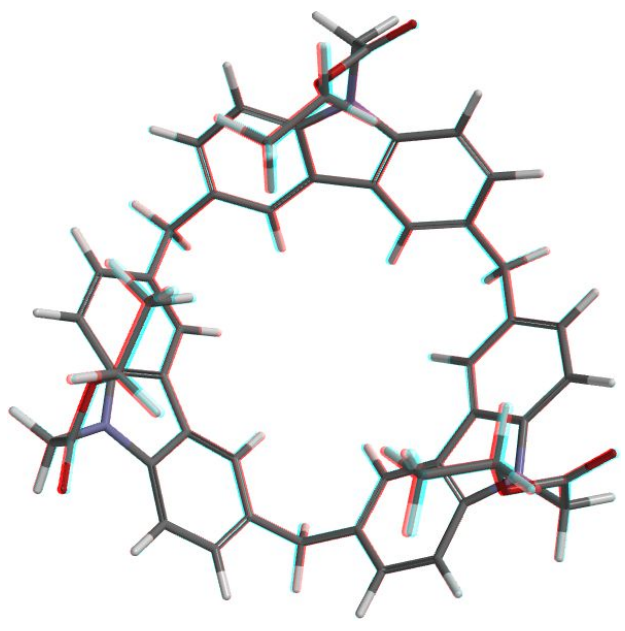

Top view

Figure S39. The optimized geometry of free $\mathbf{2}$ with the lowest energy using (MMFF) $(\mathrm{C}=$ dark grey, $\mathrm{H}=$ light grey, $\mathrm{N}=$ blue, $\mathrm{O}=$ red)

The energy-minimization of the complexation of $[2] /[$ TEA] was examined in a similar way. TEA was incorporated, with different orientations, into the cavity of several optimized 2. MMFF was again initially used to optimize geometries of the complexes and then semi-empirical method at $\mathrm{PM}_{3}$ level was used to further optimize a few selected low-energy conformations.

One representative optimized conformation of the complex of $[2] /[\mathbf{T E A}]$ with the lowest energy was listed in Figure S40.

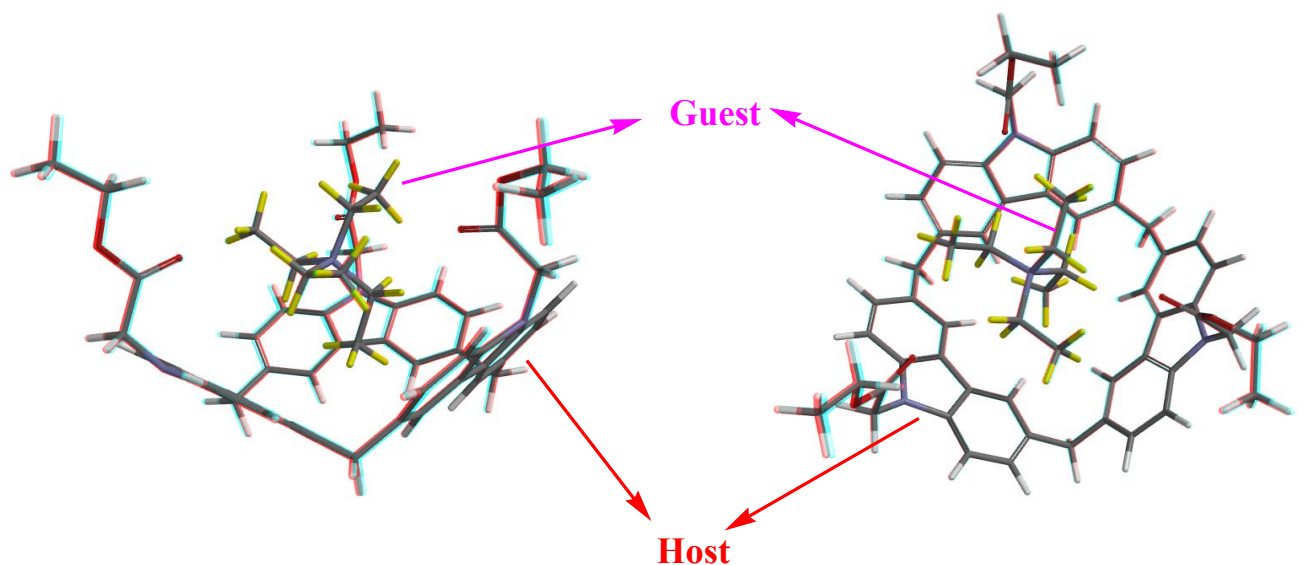

Side view

\section{Top view}

(a) Side view and top view of tube model 


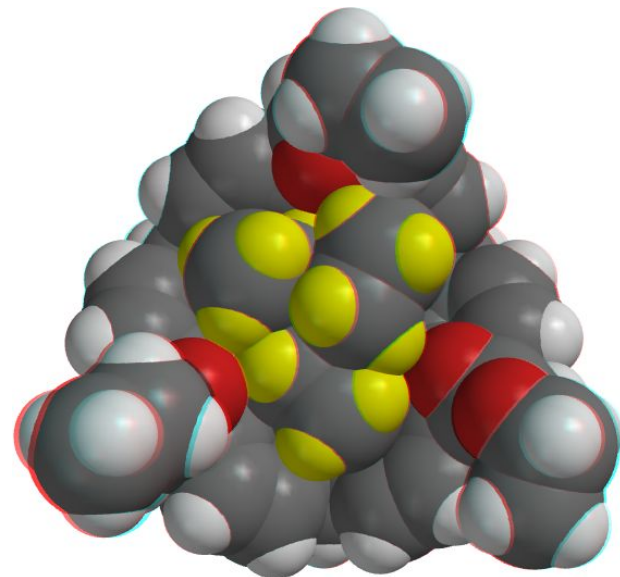

Top View

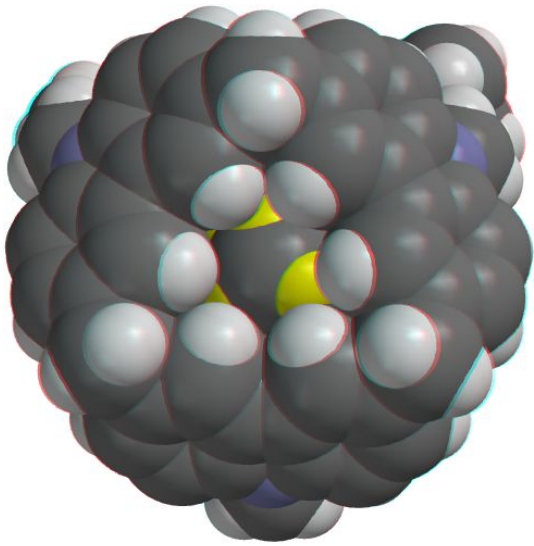

Bottom View

(b) Side view and top view of space filling model

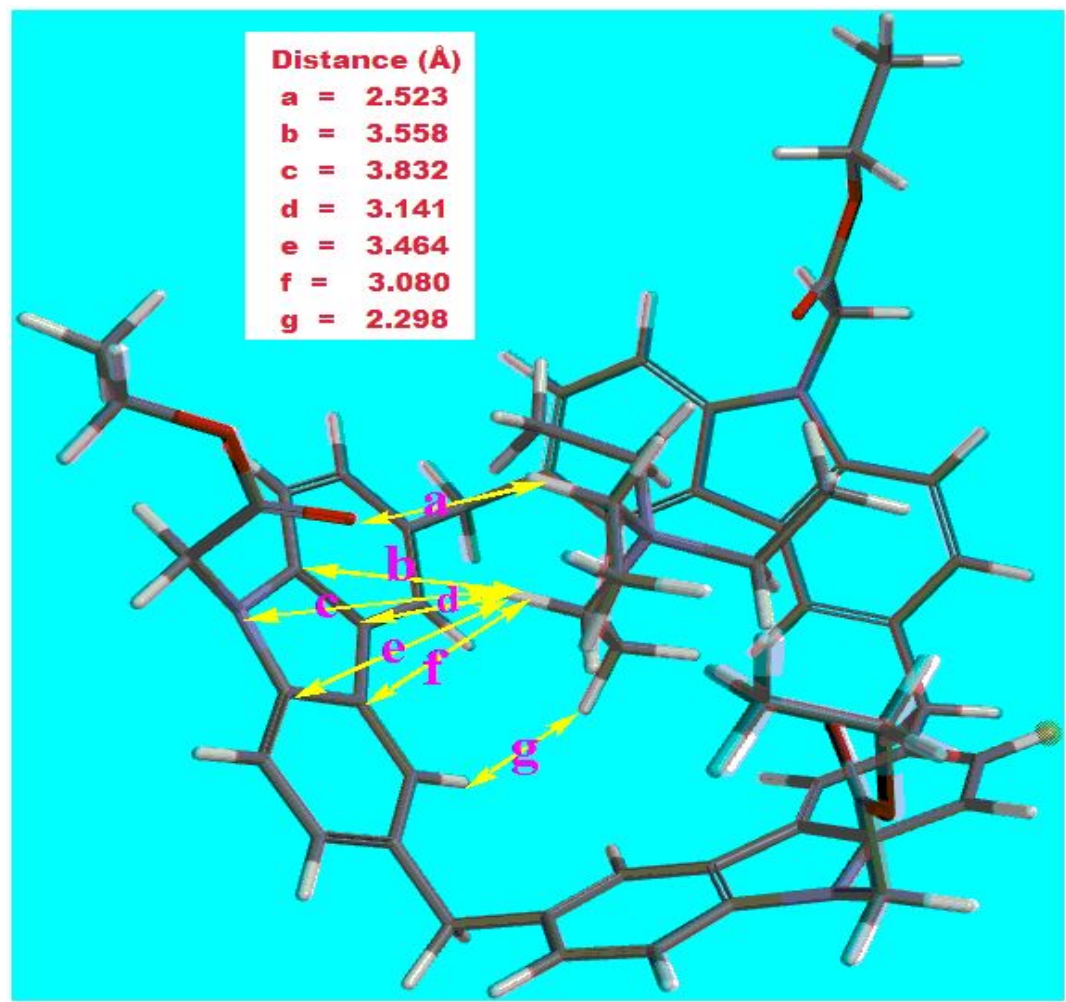

(c) The several measured distances of the optimized complex

Figure S40. The optimized geometry of the 1:1 complex of [2]/[TEA] with lowest energy using semiempirical methods at the $\mathrm{PM}_{3}$ level $(\mathrm{C}=$ dark grey, $\mathrm{H}=$ light grey, $\mathrm{N}=$ blue, $\mathrm{O}=$ red). (a) Tube Model; (b) Space Filling Model;(c) Several calculated distances.

To intuitively compare the geometrical differences between calixarene, resorcinarene, CTV and calix[3]carbazole, we further presented their visualized geometrical information together in Figure S41. To make them comparative, the lowest-energy geometries of calixarene, resorcinarene and CTV were also optimized using the Molecular Mechanics Force Field (MMFF). 

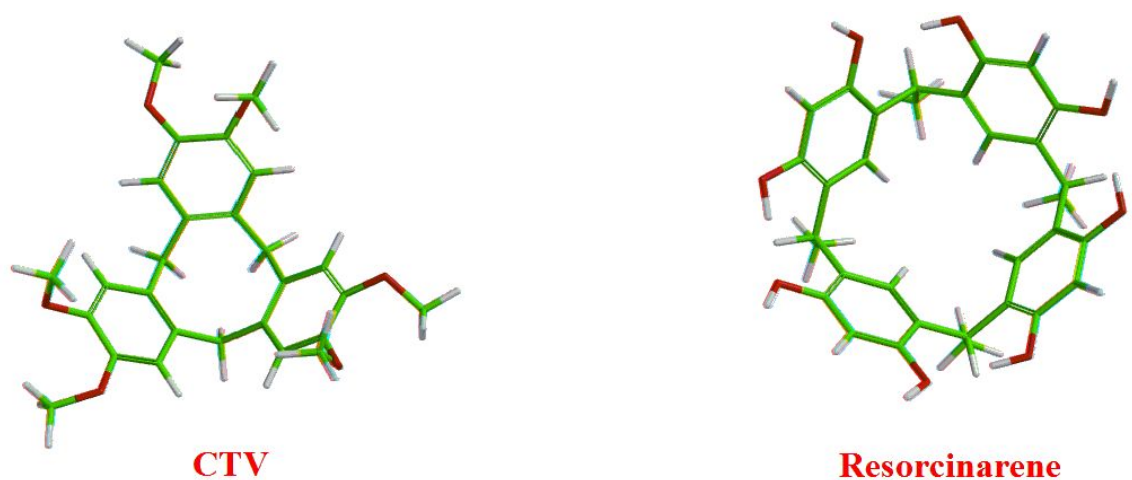

\section{Resorcinarene}
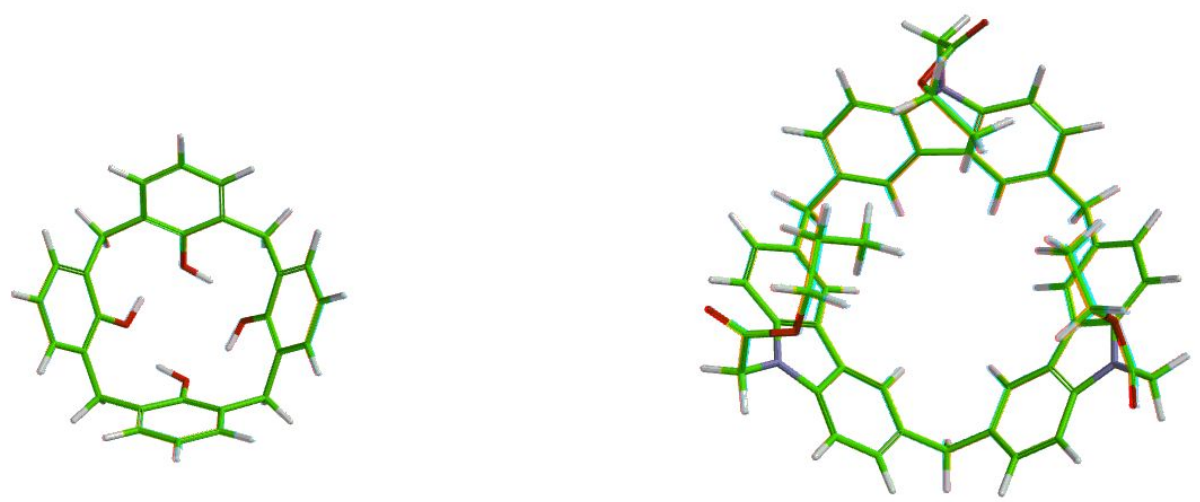

Calix[4]arene

\section{a: Top View}

Calix[3]carbazole

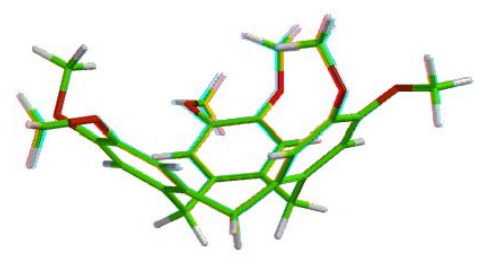

CTV

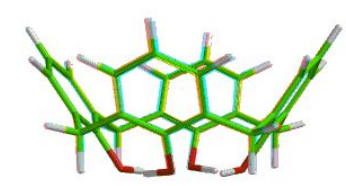

Calix[4]arene

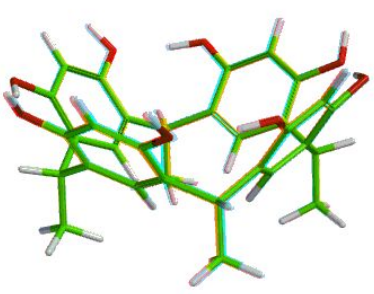

Resorcinarene

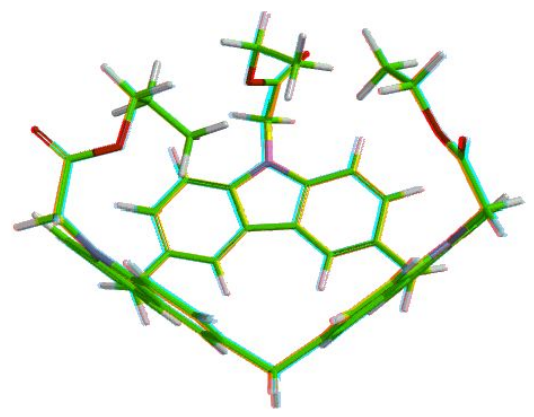

Calix[3]carbazole

\section{b: Side View}

Figure S41. The visualized geometrical differences between calixarene, resorcinarene, CTV and calix[3]carbazole. (a) Top view; (b) Side view 


\section{References}

(1) (a) Connors, K. A. Binding Constants, Wiley: New York, 1987.(b) Fielding, L. Tetrahedron, 2000, 56, 6151.(c) Gibb, C.L.D.; Stevens E.D.; Gibb, B. C. J. Am. Chem. Soc. 2001, 123, 5849

(2) (a) Yakovenko, A. V.; Boyko, V. I.; Kalchenko,V. I.; Baldini, L.; Casnati, A.; Sansone, F.; Ungaroand, R. J. Org. Chem. 2007, 72, 3223. (b) Sarri, P.; Venturi, F.; Cuda, F.; Roelens, S. J. Org. Chem. 2004, 69, 3654. (c) Botta, B.; D'Acquarica, I.; Monache, G. D. Nevola, L.; Tullo, D.; Ugozzoli, F.; Pierini F. J. Am. Chem. Soc. 2007, 129, 11202.(d) Kamieth, M.; Klärner, F.-G.; Diederich, F. Angew. Chem. Int. Ed. 1998, 37, 3303 (e) Nishimura, N.; Yoza K.; Kobayashi, K. J. Am. Chem. Soc. 2010, 132, 777. 